\title{
GEL FILTRATION CHROMATOGRAPHY OF OLIGOSACCHARIDES
}

\author{
COMPARATIVE STUDIES OF $\alpha-1,4, \alpha-1,6$ AND \\ $\alpha-1,4: \alpha-1,6$ LINKED \\ OLIGOSACCHARIDES COMPOSED OF GLUCOSE
}

\author{
by \\ FINN SCHMIDT \\ BENT STIG ENEVOLDSEN \\ Carlsberg Research Laboratory - Department of Brewing Chemistry \\ Gamle Carlsberg Vej 10 - DK-2500 Copenhagen, Valby
}

Key words: Amylose, Bio-Gel P-4, Dextran, Dextrins, Gel Filtration Chromatography,

Oligosaccharides, Pullulan, Starch, Structure

Gel filtration chromatography on Bio-Gel P-4 at $65^{\circ} \mathrm{C}$ has been used to separate oligosaccharides obtained from amylose, dextran, pullulan, and starch. The position of each oligosaccharide in the elution profile has been expressed by its $K_{a v}$ value. Each series of homologous oligosaccharides (e. g. DP 2-15/DP 3-27) gives a straight line in a plot of $-\log K_{a v}$ versus DP.

Comparison of isomeric oligosaccharides with $\alpha-1,4$ and/or $\alpha-1,6$ glucosidic linkages in a defined linear sequence reveals characteristic differences, probably related to the size (nhydrodynamic volumen) of these linear oligosaccharides $(\alpha-1,6>\alpha-1,4: a-1,6>a-1,4)$.

In contrast, isomeric branched oligosaccharides have almost identical $K_{a v}$ values close to that of the corresponding malto-oligosaccharide $(\alpha-1,4: \alpha-1,6 \sim a-1,4$ only). This permits quantitative gel filtration chromatography according to DP of acid and enzymic hydrolyzates of starch.

Cyclic, a-1,4 linked oligosaccharides (Schardinger dextrins) appear in size to be considerably smaller than the corresponding malto-oligosaccharides.

The results show that although oligosaccharides are eluted in approximately the reverse order of their molecular weight the fine structure of the oligosaccharide seems to determine its position in the elution profile. 


\section{INTRODUCTION}

Gel filtration chromatography* on polyacrylamide gels (Bio-Gel P-2, etc.) using water as eluent is a powerful method of separating oligosaccharides $(13,14,17)$. This method has been developed into an automatic and quantitative technique (11), which permits the separation and determination of a series of homologous oligosaccharides according to their molecular weight or DP (degree of polymerization). This method has also been used to separate the oligosaccharides in acid (16) and enzymic (5) hydrolyzates of starch according to their molecular weight, although such hydrolyzates contain several isomers (9). In contrast, the isomeric disaccharides maltose and isomaltose as well as the isomeric trisaccharides maltotriose and isomaltotriose can be separated from oneanother on Bio-Gel P-2(11).

However, comparative studies on the gel filtration chromatographic behaviour of isomeric oligosaccharides have been performed to a limited extent only (e. g. by BROWN \& Chitcmbo (3)) and have been restricted to oligosaccharides of DP 2-10.

Oligosaccharides may differ in their monosaccharide units, in the type and sequence of glycosidic linkages, or both. The present study has been confined to oligosaceharides composed of glucose only and with $\alpha-1,4$ and/or $a-1,6$ glucosidic linkages. The oligosaccharides include: i) malto-oligosaccharides ( $\alpha-1,4$ only) derived from amylose; ii) isomalto-oligosaccharides ( $\alpha-1,6$ only) derived from dextran; iii) linear, $\alpha-1,4 ; \alpha-1,6 \quad$ linked oligosaccharides derived from pullulan; iv) branched, $\alpha-1,4: \alpha-1,6$ linked oligosaccharides derived from amylopectin; and $v$ ) cyclic, $\alpha-1,4$ linked oligosaccharides (Schardinger dextrins). It has been the object of the present study to compare the gel filtration chromatographic behaviour of these oligosaccharides, using the malto-oligosaccharides as a common reference, and to correlate characteristic differences with the structure of these oligosaccharides. A preliminary account of this study has been given elsewhere (15).

\section{MATERIALS AND METHODS}

\subsection{Malto-oligosaccharides}

were prepared by partial, acid hydrolysis of the a-1,4 linked glucan, amylose (Merck). The weight distribution pattern of the maltooligosaccharides (maltose $=\mathrm{M}_{2}$, maltotriose $=$ $M_{3}, \ldots, M_{n}$ ) plus glucose $(G)$ is shown in Fig. 2.

\subsection{Isomalto-oligosaccharides}

were prepared by partial, acid hydrolysis of the $\alpha-1,6$ linked glucan, dextran (Pharmacia). The weight distribution pattern shown in Fig. 3 represents isomaltopentaose $\left(\mathrm{IM}_{3}\right)$ and higher oligomers of the above mentioned hydrolyzate, to which isomaltotetraose $\left(\mathrm{IM}_{4}\right)$, isomaltotriose $\left(\mathrm{IM}_{3}\right)$, isomaltose $\left(\mathrm{IM}_{2}\right)$ (obtained by preparative paper chromatography) and glucose (G) were added.

\subsection{Linear, $\alpha-1,4: \alpha-1,6$ linked oligosaccharides} were prepared from pullulan, a linear $\alpha$-glucan composed of maltotriose units linked thead-totail through $\alpha-1,6$ linkages. Except for the chain-ends of the linear polymer, pullulan may also be visualized as being composed of repeating units of $\alpha-1,4$ linked panose $\left(6^{2}-\alpha-\right.$ glucosyl-maltose) or repeating units of $a-1,4$ linked isopanose (6- $\alpha$-maltosyl-glucose). Thus three types of oligosaccharides can be anticipated from pullulan:

Type B: the reducing chain-end triplet is a maltotriose unit

Type $P$ : the reducing chain-end triplet is a panose unit

Type IP: the reducing chain-end triplet is an isopanose unit.

Each type may in turn be subdivided into three series of homologous oligosaccharides termi-

* Gel filtration chromatography is a method of separating molecules according to their size in solution. It employs aqueous solvents and hydrophilic column packings. Gel permeation chromatography performs the same kind of separation but usually employs organic solvents and hydrophobic column packings (2). 


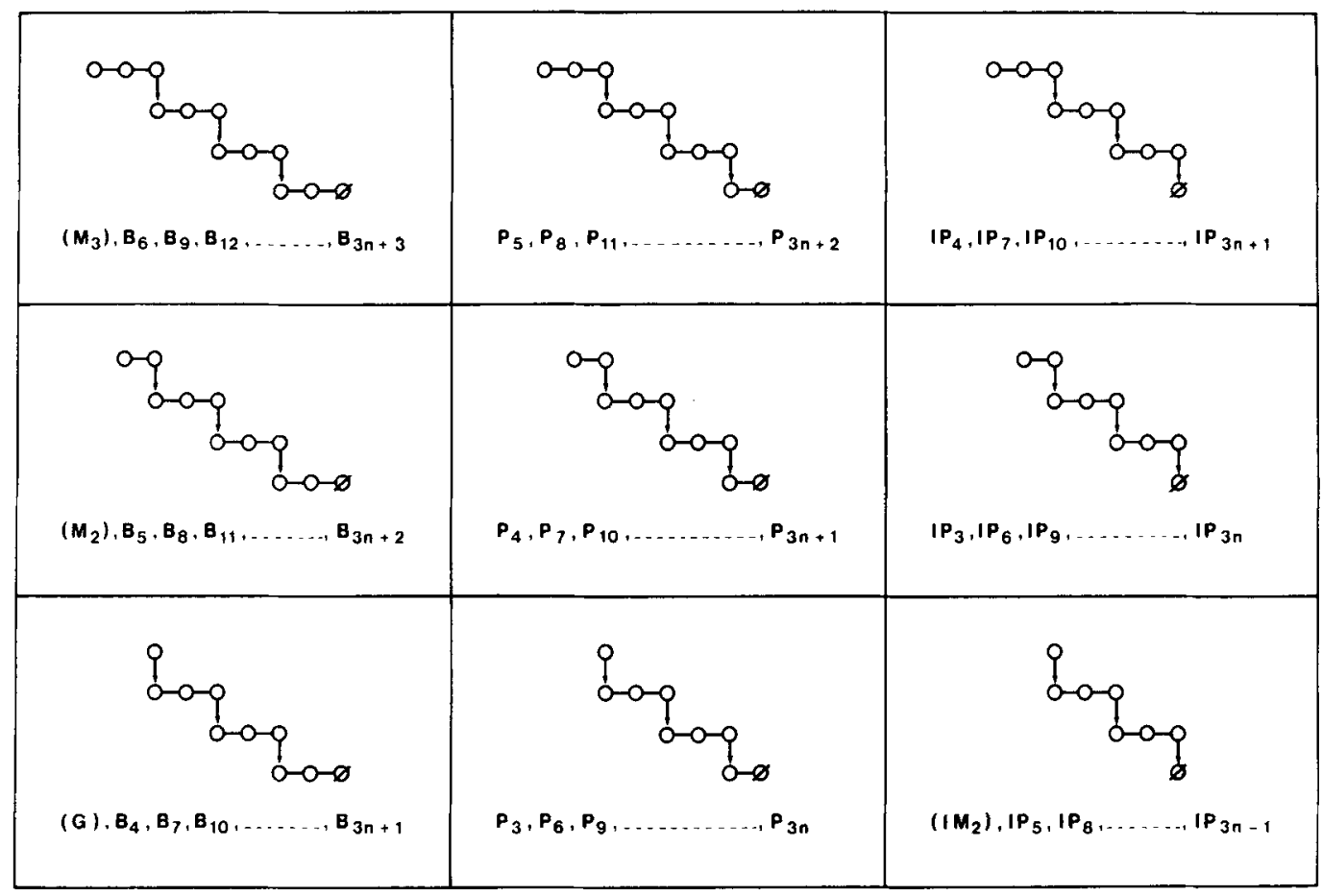

Figure 1. Schematic representation of the nine possible series of homologous oligosaccharides which may be derived from the linear a-glucan, pullulan, a polysaccharide composed of $\alpha-1,6$ linked maltotriose units.

Symbols are used as follows: 0 , glucose residue; $\emptyset$, reducing glucose residue; $, a-1,4$ linkage; $\downarrow, a-1,6$ linkage; subscripts $2,3,4,5 \ldots \ldots, 3 n-1,3 n, 3 n+1$, $3 n+2,3 n+3$ refer to degree of polymerization (DP) or number of glucose residues in a given oligosaccharide or series thereof. Furthermore $\mathrm{n}$ equals the number of $a-1,6$ linkages in a given oligosaccharide. $G, \mathbf{M}_{2}$ and $\mathrm{IM}_{2}$ signify glucose, maltose and isomaltose. $M_{3}$, $\mathrm{P}_{3}$ and $\mathrm{IP}_{3}$ signify maltotriose, panose and isopanose. $B, P$ and IP indicate pullulan derived oligosaccharides having, respectively, a maltotriose, a panose and an isopanose unit as the reducing chain-end triplet.

nated at their nonreducing chain-end by an $\alpha$ 1,6 linked maltotriose, maltose and glucose unit, respectively. Structural representatives of the nine possible series of homologous oligosaccharides are shown in Fig. 1.

Through the specific action of $\beta$-amylase 3.2.1.2), pullulanase (EC 3.2.1.41) and isopullulanase (EC 3.2.1.57) it is possible to produce six of the above mentioned series of homologous oligosaccharides corresponding to the B series and IP series (10). Isopullulanase is not freely available, and the digestion with this enzyme was kindly performed by Dr. Y. Sakano (Tokyo Noko University, Japan) with our specimen of pullulan. Since each member in a series of homologous oligosaccharides derived from pullulan differ from the following member by 3 glucose residues, this greatly facilitates their separation by gel filtration chromatography, and makes it possible to identify members above DP 15, e. g. $B_{27}$ (Bio-Gel P-4) and $\mathrm{B}_{45}$ (Bio-Gel P-6).

The following three series have been obtained free of interfering components:

$B_{3 n+3^{-}}$series: $B_{6}, B_{9}, B_{12}, B_{15}, B_{18}, B_{21}, B_{24}, B_{27}$, etc. (Fig. 5)

$\mathrm{IP}_{3 \mathrm{n}}$-series: $\mathrm{IP}_{3}, \mathrm{IP}_{6}, \mathrm{IP}_{9}, \mathrm{IP}_{12}, \mathrm{IP}_{15}, \mathrm{IP}_{18}, \mathrm{IP}_{21}$, $\mathrm{IP}_{24}, \mathrm{IP}_{27}$, etc. (Fig. 6)

$B_{3 n+1}$-series: $B_{4}, B_{7}, B_{10}, B_{13}, B_{16}, B_{19}, B_{22}, B_{2 s}$, etc. (Fig. 8).

The other three series have so far only been obtained in combinations of two or more series, thus only the first three members listed below have been resolved:

IP $3 \mathrm{n+1}$-series: $\mathrm{IP}_{4}, \mathrm{IP}_{7}, \mathrm{IP}_{10}$, etc.

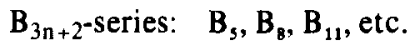

$\mathrm{IP}_{3 \mathrm{n}-1}$-series: $\mathrm{IP}_{5}, \mathrm{IP}_{8}, \mathrm{IP}_{11}$, etc. 
In addition to the above mentioned enzymic hydrolyzates of pullulan, a partial, acid hydrolysis was performed. This gave linear, $a$ 1,4:a-1,6 linked oligosaccharides of DP $3,6,9$, $\ldots$ as the major components, and DP $4,5,7,8$, $10,11, \ldots$ as minor components, see Fig. 9. Isolation by paper chromatography and tentative structural analysis indicated a preference for hydrolysis of the $a-1,4$ linkages compared to the $\alpha-1,6$ linkages, corresponding to the series:

$P_{3 n}$-series: $\quad P_{3}, P_{6}, P_{9}$, etc.

IP $\mathrm{P}_{3 \mathrm{n}}$-series: $\quad \mathrm{IP}_{3}, \mathrm{IP}_{6}, \mathrm{IP}_{9}$, etc.

$\mathrm{P}_{3 \mathrm{n}+1}$-series: $\mathrm{P}_{4}, \mathrm{P}_{7}, \mathrm{P}_{10}$, etc.

$I P_{3 n-1}$-series: $I P_{5}, I P_{B}, I P_{11}$, etc.

\subsection{Branched, $\alpha-1,4: \alpha-1,6$ linked oligosaccharides} derived from amylopectin are present in acid and enzymic hydrolyzates of starch. The oligosaccharides chosen for this study were those present in a commercial source of glucose syrup (a partial, acid hydrolyzate of wheat starch) and in beer (see also ENEVOLDSEN \& SCHMIDT (9)).

\subsection{Cyclic, $\alpha-1,4$ linked oligosaccharides}

(Schardinger dextrins) were obtained from the following sources: $\alpha$-Schardinger dextrin (cyclomaltohexaose) free of $\beta$-Schardinger dextrin (cyclomaltoheptaose) was obtained from Sigma; $\alpha$-Schardinger dextrin containing about $20 \% \beta$-Schardinger dextrin (see Fig. 11) and pure $\beta$-Schardinger dextrin were obtained from Pierce.

\subsection{Other carbohydrates}

used were: glucose (BDH), maltose (Fluka), isomaltose (Koch-Light), panose (6 ${ }^{2}-\alpha$-glucosylmaltose) (Koch-Light) and Dextran T-150 (Pharmacia).

Furthermore, in order to confirm the identity of the individual peaks in the gel filtration chromatograms (see below) several members of the above mentioned series of homologous oligosaccharides were isolated by paper chromatography and subjected to chemical and enzymic analyses.

\subsection{Bio-Gels}

Bio-Gel P-2, -400 mesh (Control No. 11324), Bio-Gel P-4, -400 mesh (Control No. 41868) and Bio-Gel P-6, -400 mesh (Control No. 44958) were obtained from Bio-Rad Laboratories. After swelling in de-ionized water the spherical particles were fractionated to obtain a more narrow size-distribution $(31-45 \mu \mathrm{m})$ of the gel particles, as previously described (9). Unless otherwise stated the separations in this study were performed on Bio-Gel P-4.

\subsection{Gel filtration chromatography}

was performed as described by ENEVOLDSEN \& SCHMIDT (9) at $65^{\circ} \mathrm{C}$, and the parameters of the Bio-Gel P-4 column are given in Table $I$. The concentration of oligosaccharides in the eluate was determined by continuous recording of the absorbance at $420 \mathrm{~nm}$ after colorimetric reaction with orcinol-sulphuric acid (11).

$V_{t}$ is the total volume of the gel bed, and has been determined from the actual height of the gel bed and the diameter of the tube. The diameter of the tube $(8.95 \mathrm{~mm})$ has been determined - before packing of the tube - by weighing the water content of the tube.

$V_{o}$ is the void volume of the column, and has been determined from the elution volume (see below) of Dextran T-150.

$V_{e}$ (the elution volume) is the volume of eluate measured from the time when the sample enters the column until the component in question is eluted in its peak concentration from the column. Thus $V_{t}>V_{e} \geqq V_{0}$. The elution volumes, $V_{e}$ 's, have been determined in the following way. Based on the recorder trace of the elution profile the distance on the recorder paper from the point of application to the peak concentration of a given component is measured. This distance is divided by the recorder paper speed $(30 \mathrm{~mm} / \mathrm{h})$, and multiplied by the flow-rate $(10.8 \mathrm{ml} / \mathrm{h})$. From this gross elution volume the elution volume, $V_{e}$, is obtained by subtracting the following three volumes: the volume of the inlet tubing, the volume of the outlet tubing and the volume corresponding to the hold-up time in the detection system. 
Table I

Parameters of Bio-Gel P-4 column.

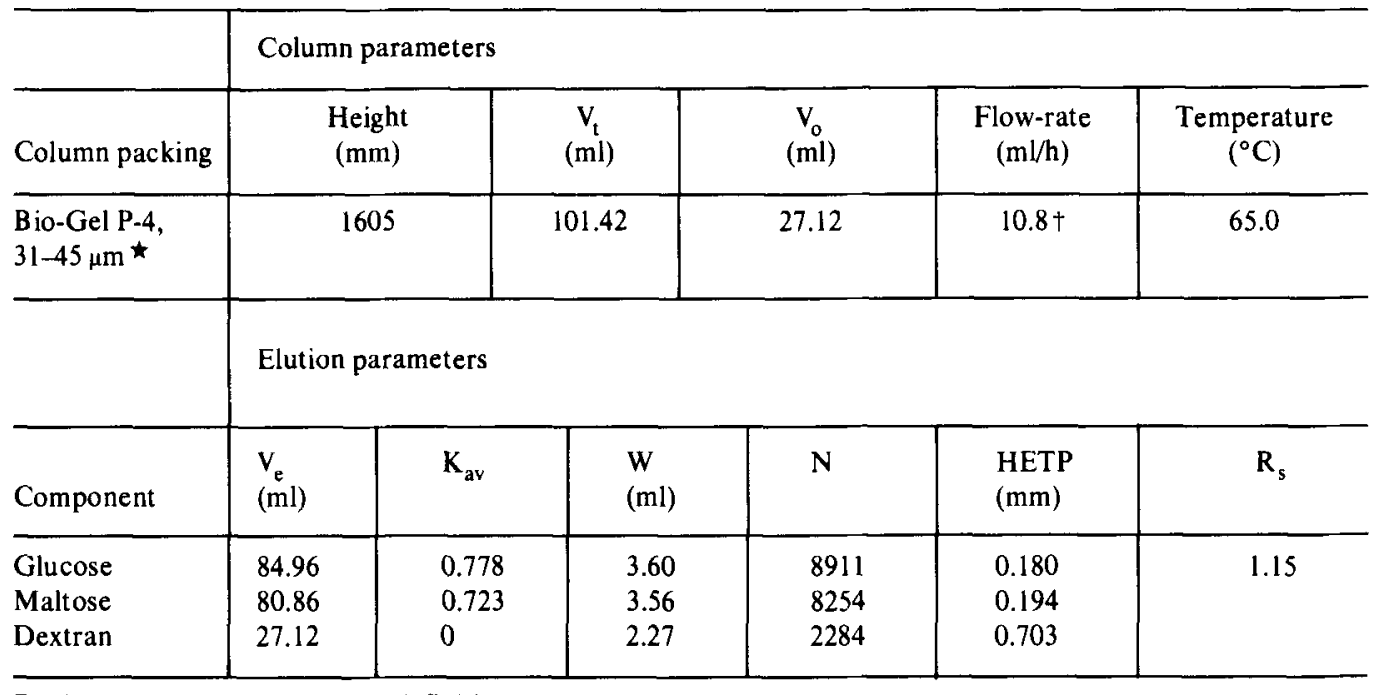

For symbols, abbreviations and definitions see text.

$\star$ Bio-Gel P-4, -400 mesh, further fractionated before use (see text).

† Although all separations have been performed at $65^{\circ} \mathrm{C}$, the flow-rate as well as the elution volumes, $V_{e}$ 's, including $\mathrm{V}_{\mathrm{o}}$ have been expressed corresponding to the volume of water at $20^{\circ} \mathrm{C}$.

$K_{a v}$ values: various indices $\left(\mathrm{V}_{\mathrm{e}} / \mathrm{N}_{\mathrm{o}}, \mathrm{K}_{\mathrm{av}}, \mathrm{K}_{\mathrm{d}}\right.$, etc. $)$ may be used to specify the position of a given component (the apex of a given peak) in the elution profile. $K_{a v}=\left(V_{e}-V_{o}\right) /\left(V_{t}-V_{o}\right)(12)$ appears to be a convenient index and has been used throughout this study. $K_{a v}=\left[1-V_{m} /\left(V_{t}\right.\right.$ $\left.V_{o}\right)$ ] $K_{d}$, where $V_{m}$ is the volume which the gel matrix occupies.

The performance and separation efficiency of the column (given in Table I) have been expressed using the following elution parameters. $W$ is the width of a peak, and has been determined by drawing the tangents in the inflection points and measuring the distance of the corresponding intersection on the (hypothetical) baseline below the peak. $\mathrm{N}$ is the total number of theoretical plates in the column, and has been determined as $\left(4 \cdot \mathrm{V}_{\mathrm{e}} / \mathrm{W}\right)^{2}$. HETP is the height equivalent to a theoretical plate, and has been determined by dividing the height of the column with $N$. $R_{s}$ is the resolution between two peaks, given as $2\left(V_{e}{ }^{\prime \prime}-V_{e}\right) /$ (W'+ W').

Quantitative gel filtration chromatography is used routinely in our laboratory for determin- ing the weight distribution of starch derived dextrins in beer etc. A given column is normally used for a period of time, based on the efficiency of the column as expressed by the resolution of glucose and maltose (see Table I).

For every 10 runs an external standard, containing Dextran T-150, maltose and glucose, has been applied, and from the elution profile the resolution, $\mathbf{R}_{\mathrm{s}}$, between glucose and maltose has been determined. For a freshly packed column $R_{S}$ values of about 1.6 may be obtained, and then it will decrease with time. After about 4 months of continuous use, $R_{s}$ could have come down to 1.0, which means that the column is inadequate for our purpose. The gel material is either repacked or discarded.

The Bio-Gel P-4 column used in the present study gave, freshly packed, $\mathbf{R}_{\mathrm{s}}=1.6$. It was used for 4 weeks, repacked, and after 2 weeks it gave $\mathbf{R}_{\mathrm{s}}=1.15$, as stated in Table I. All separations shown were performed consecutively within the following two weeks. 


\section{RESULTS}

\subsection{Linear, $\alpha-1,4$ linked oligosaccharides:}

The malto-oligosaccharides have been used as a common reference in the comparative study of the oligosaccharides in question. To ensure that the separation characteristics of the column did not change with time during the about thirty separations included in this study, the $\mathbf{M}_{\mathrm{n}}$-series was analysed at the beginning, half-way through, and at the end of the experiment. The elution profile from the first of these three separations of the $\mathrm{M}_{\mathrm{n}}$-series is shown in Fig. 2 . $\mathrm{V}_{\mathrm{e}}$ 's and $\mathrm{K}_{\mathrm{av}}$ 's for the first run as well as the -log $\mathrm{K}_{\mathrm{av}}$ values for the three separations and their average value are listed in Table II. The apparent equidistance of the $-\log \mathrm{K}_{\mathrm{av}}$ values indicates a linear relationship of DP and $-\log K_{\mathrm{iv}}$. The results of linear regression analysis are given in Table II as expressed by the slope, the intersection with the ordinate and the correlation coefficient of the straight line. Glucose has not been included, since it does not contain the characteristic $\alpha-1,4$ linkage of the $M_{n}$-series. The straight line based on the average $-\log K_{a v}$ values versus DP is shown in Fig. 4.

\subsection{Linear, $\alpha-1,6$ linked oligosaccharides :}

The isomalto-oligosaccharides, the $\mathrm{IM}_{\mathrm{n}}$-series, were analysed twice and the elution profile from the first run of this series of $\alpha-1,6$ linked glucose residues is shown in Fig. 3. The elution parameters $V_{e}$ and $K_{a v}$ for this series and the $-\log K_{a v}$ values from the two separations performed as well as the average $-\log \mathrm{K}_{\mathrm{av}}$ value are given in Table III. Glucose has not been included in this series since it does not contain the characteristic $\alpha-1,6$ linkage of the $\mathrm{IM}_{n}$ series. The straight line based on the average $-\log K_{a v}$ values versus DP for the $I_{\mathrm{n}}$-series is shown in Fig. 4.

The results of the repeated separations reveal that the $K_{\mathrm{av}}$ values are reproducible (at least for a particular set of conditions) and comparison of the straight lines for the $M_{n}$-series and the $\mathrm{IM}_{\mathrm{n}}$-series in Fig. 4 shows a characteristic difference of the two series of homologous oligosaccharides. The intersections with the ordinate are quite similar whereas the slopes of the two straight lines differ.

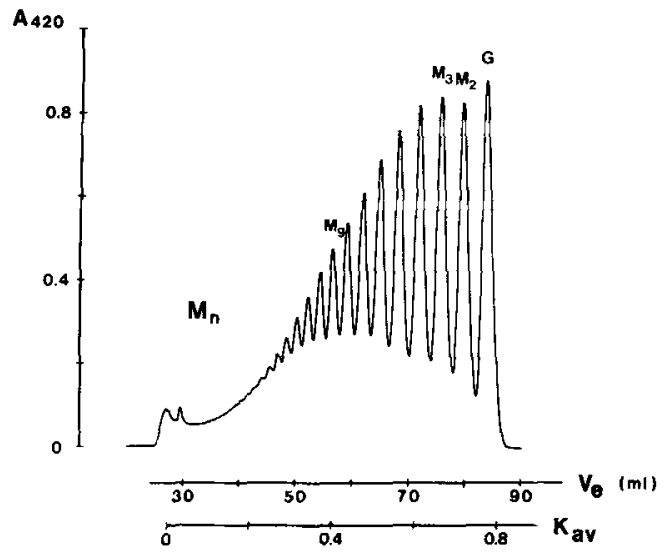

Figure 2. Elution profile of the malto-oligosaccharides, $\mathbf{M}_{\mathbf{n}}$-series.

The sample was obtained by partial, acid hydrolysis of the $\alpha-1,4$ linked glucan, amylose. The peaks indicated are: glucose $(G)$, maltose $\left(M_{2}\right)$, maltotriose $\left(\mathrm{M}_{3}\right)$ and maltononaose $\left(\mathrm{M}_{9}\right)$.

Conditions of separation: Bio-Gel P-4, -400 mesh, further fractionated before use; tube: $9 \times 1690 \mathrm{~mm}$; flow-rate: $10.8 \mathrm{ml} / \mathrm{h}$; sample volume: $20 \mu \mathrm{l}$; eluent: water; recorder paper speed: $30 \mathrm{~mm} / \mathrm{h} ; \mathrm{V}_{\mathrm{t}}: 101.42 \mathrm{ml}$; $V_{o}: 27.12 \mathrm{ml}$. The ordinate is absorbance at $420 \mathrm{~nm}$ after reaction of a constant fraction of about $90 \%$ of the eluate with orcinol-sulphuric acid; the remaining $10 \%$ of the eluate is discarded. The two abscissae below the recorder trace refer to the elution volumes, $\mathrm{V}_{\mathrm{e}}$ 's, and their corresponding $\mathrm{K}_{\mathrm{av}}$ values.

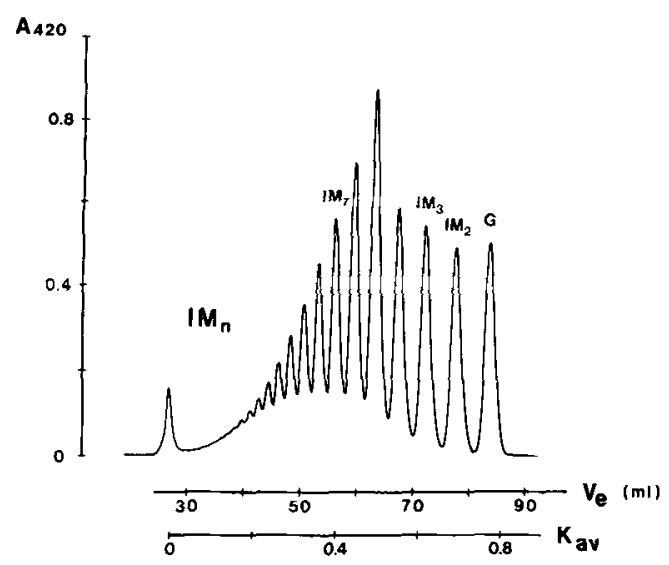

Figure 3. Elution profile of the isomalto-oligosaccharides, $\mathrm{IM}_{\mathrm{n}}$-series.

The sample was obtained by partial, acid hydrolysis of the $\alpha-1,6$ linked glucan, dextran. The peaks indicated are: glucose $(G)$, isomaltose $\left(\mathrm{IM}_{2}\right)$, isomaltotriose $\left(\mathbf{I M}_{3}\right)$ and isomaltoheptaose $\left(\mathbf{I M}_{7}\right)$. Conditions as in Figure 2. 
Elution parameters for the malto-oligosaccharides and linear regression analysis of $-\log \mathrm{K}_{\mathrm{dv}}$ versus DP.

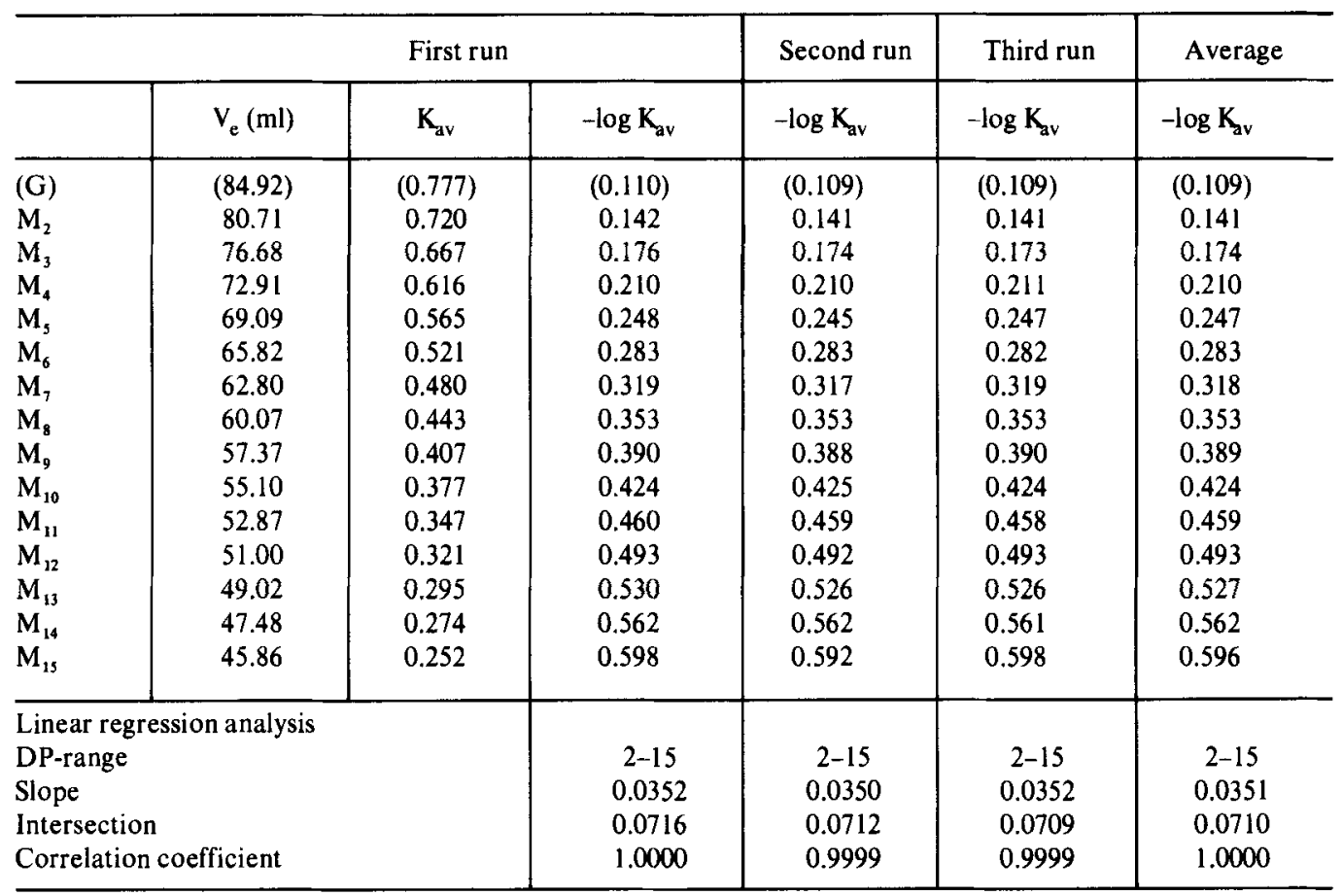

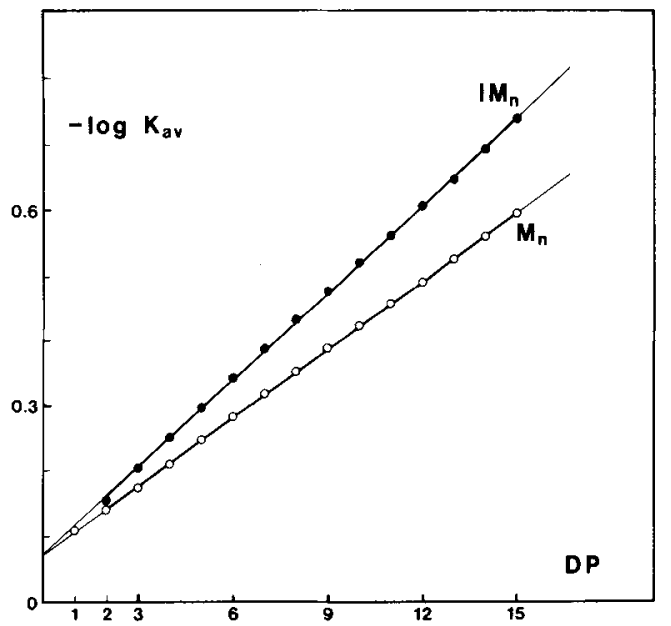

Figure 4. - $\log \mathrm{K}_{\mathrm{ay}}$ versus $\mathrm{DP}$ for the $\mathrm{M}_{\mathrm{n}}$ - and $1 \mathrm{M}_{\mathrm{n}}$ series.

Plot of the average values of $\log K_{a v}$ versus DP for the malto- and isomalto-oligosaccharides, and the two straight lines obtained by linear regression analysis (DP 2-15). The straight line for the malto-oligosaccharides is given by: slope 0.0351 ; intersection 0.0710 ; correlation coefficient 1.0000 . The straight line for the isomalto-oligosaccharides is given by: slope 0.0446 ; intersection 0.0732 ; correlation coefficient 0.9998 .
Comparison of the isomeric malto-oligosaccharides and isomalto-oligosaccharides shows that the $\alpha-1,6$ linkages seem to increase the apparent size of the molecule relative to the $a-1,4$ linkages in these oligosaccharides composed of glucose. Thus oligosaccharides of the same apparent size are not necessarily isomeric. When the two elution profiles of Fig. 2 and Fig. 3 are superimposed one observes that isomaltoheptaose $\left(\mathrm{IM}_{7}\right)$ occupies the same position in the elution profile as does maltononaose $\left(M_{9}\right)$ which is also seen from the $K_{a v}$ values or $-\log \mathrm{K}_{\mathrm{av}}$ values in Table II and Table III.

\subsection{Linear, $\alpha-1,4: \alpha-1,6$ linked oligosaccharides:} Oligosaccharides with $\alpha-1,4$ and $\alpha-1,6$ linkages in a defined linear sequence can be derived from the polysaccharide pullulan as already outlined. The separation of the series of oligosaccharides obtained from the action of pullulanase on pullulan is shown in Fig. 5. Similarly the separation of the series of oligosaccharides obtained from the action of 
F. Schmidt \& B. S. ENEvoldSEN: Gel Filtration Chromatography of Oligosaccharides

Table III

Elution parameters for the isomalto-oligosaccharides and linear regression analysis of $-\log K_{a v}$ versus DP.

\begin{tabular}{|c|c|c|c|c|c|}
\hline & \multicolumn{3}{|c|}{ First run } & \multirow{2}{*}{$\frac{\text { Second run }}{-\log \mathrm{K}_{\mathrm{av}}}$} & \multirow{2}{*}{$\frac{\text { Average }}{-\log K_{a v}}$} \\
\hline & $\mathrm{V}_{\mathrm{e}}(\mathrm{ml})$ & $\mathbf{K}_{\mathrm{av}}$ & $-\log \mathrm{K}_{\mathrm{av}}$ & & \\
\hline (G) & $(84.92)$ & $(0.778)$ & $(0.109)$ & $(0.107)$ & $(0.108)$ \\
\hline $\mathrm{IM}_{2}$ & 79.06 & 0.699 & 0.155 & 0.155 & 0.155 \\
\hline $\mathrm{IM}_{3}$ & 73.48 & 0.624 & 0.205 & 0.203 & 0.204 \\
\hline $\mathrm{IM}_{4}$ & 68.70 & 0.560 & 0.252 & 0.251 & 0.252 \\
\hline $\mathrm{IM}_{5}$ & 64.49 & 0.503 & 0.298 & 0.296 & 0.297 \\
\hline $\mathrm{IM}_{6}$ & 60.75 & 0.453 & 0.344 & 0.343 & 0.344 \\
\hline $\mathrm{IM}_{7}$ & 57.48 & 0.409 & 0.389 & 0.388 & 0.389 \\
\hline $\mathrm{IM}_{8}$ & 54.35 & 0.366 & 0.436 & 0.431 & 0.434 \\
\hline $\mathrm{IM}_{9}$ & 51.79 & 0.332 & 0.479 & 0.478 & 0.479 \\
\hline $\mathrm{IM}_{10}$ & 49.38 & 0.300 & 0.523 & 0.521 & 0.522 \\
\hline $\mathrm{IM}_{11}$ & 47.30 & 0.272 & 0.566 & 0.562 & 0.564 \\
\hline $\mathrm{IM}_{12}$ & 45.32 & 0.245 & 0.611 & 0.605 & 0.608 \\
\hline $\mathrm{IM}_{13}$ & 43.81 & 0.225 & 0.649 & 0.648 & 0.649 \\
\hline $\mathrm{IM}_{14}$ & 42.08 & 0.201 & 0.696 & 0.692 & 0.694 \\
\hline $\mathrm{IM}_{15}$ & 40.64 & 0.182 & 0.740 & 0.740 & 0.740 \\
\hline \multicolumn{6}{|c|}{ Linear regression analysis } \\
\hline \multicolumn{3}{|c|}{ DP-range } & $2-15$ & $2-15$ & $2-15$ \\
\hline \multicolumn{3}{|c|}{ Slope } & 0.0447 & 0.0445 & 0.0446 \\
\hline \multicolumn{3}{|c|}{ Intersection } & 0.0734 & 0.0724 & 0.0732 \\
\hline \multicolumn{3}{|c|}{ Correlation coefficient } & 0.9998 & 0.9998 & 0.9998 \\
\hline
\end{tabular}

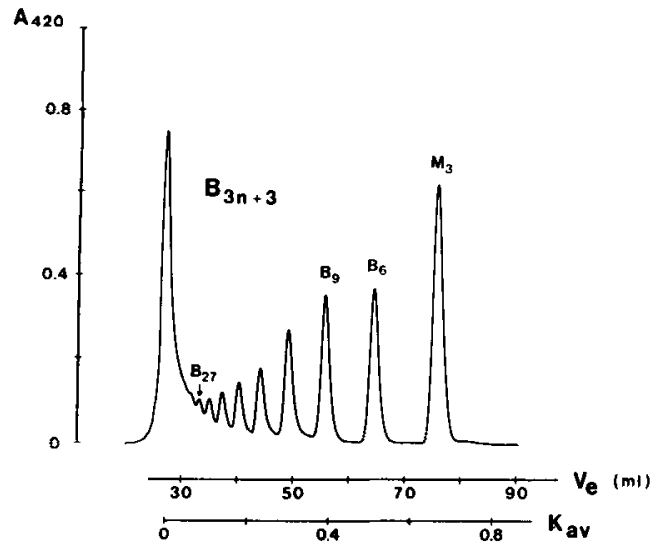

Figure 5. Elution profile of the $B_{3 n+3}$-series.

The sample was obtained by partial, enzymic hydrolysis of pullulan by pullulanase (EC 3.2.1.41). The peaks indicated are: maltotriose $\left(\mathrm{M}_{3}\right), 6^{3}-\alpha-\mathrm{mal}-$ totriosyl-maltotriose $\left(B_{6}\right), 6^{3}-\alpha-\left(6^{3}-\alpha\right.$-maltotriosyl-maltotriosyl)-maltotriose $\left(B_{9}\right)$ and the higher homologue, the heptacosasaccharide $\left(B_{27}\right)$. Conditions as in Figure 2.

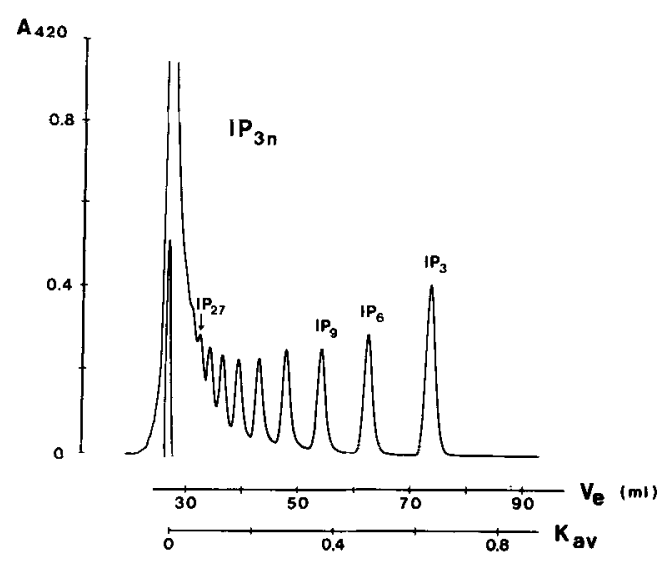

Figure 6. Elution profile of the $\mathrm{IP}_{3 \mathrm{n}}$-series.

The sample was obtained by partial hydrolysis of pullulan by isopullulanase (EC 3.2.1.57). The peaks indicated are: isopanose $\left(\mathrm{IP}_{3}\right), 6-\alpha-\left(6^{3}-\alpha-\right.$ maltosyl-maltotriosyl)-glucose $\left(\mathrm{IP}_{6}\right)$, 6-a-(6- $6^{3}-\alpha-\left(6^{3}-\alpha-\right.$-maltosyl-maltotriosyl)-maltotriosyl)-glucose (IP, and the higher homologue, the heptacosasaccharide $\left(\mathrm{IP}_{27}\right)$. Conditions as in Figure 2. 
Table IV

$-\log K_{a v}$ values for the $B_{3 n+3}$-series, panose $\left(P_{3}\right)$ and the $I_{3 n}$-series and linear regression analysis of $-\log K_{n v}$ versus $D P$.

\begin{tabular}{l|c|c|c}
\hline \multirow{2}{*}{ DP } & \multicolumn{3}{|c}{$-\log \mathrm{K}_{\mathrm{av}}$} \\
\cline { 2 - 4 } & $\mathrm{B}_{3 \mathrm{n}+3}$ & $\mathrm{P}_{3 \mathrm{n}}$ & $\mathrm{IP}_{3 \mathrm{n}}$ \\
\hline 3 & $(0.174)$ & 0.186 & 0.194 \\
6 & 0.287 & - & 0.311 \\
9 & 0.402 & - & 0.425 \\
12 & 0.512 & - & 0.538 \\
15 & 0.620 & - & 0.646 \\
18 & 0.729 & - & 0.753 \\
21 & 0.831 & - & 0.859 \\
24 & 0.940 & - & 0.971 \\
27 & 1.046 & - & 1.077 \\
\hline DP-range & $6-27$ & 3 & $3-27$ \\
Slope & 0.0360 & & 0.0366 \\
Intersection & 0.0771 & & 0.0920 \\
Corr. coeff. & 0.9999 & & 0.9999 \\
\hline
\end{tabular}

isopullulanase on pullulan is shown in Fig. 6. These series of homologous oligosaccharides have been termed the $B_{3 n+3}$-series and the $\mathrm{IP}_{3 \mathrm{n}}$ series, respectively. Maltotriose $\left(\mathrm{M}_{3}\right)$ is not considered as a representative member of the $B_{3 n+3}$-series, since it does not contain an $a-1,6$ linkage, and already (see Table II) has been treated as a member of the $M_{n}$-series. The $\mathrm{B}_{3 \mathrm{n}+3}$-series and the $\mathrm{IP}_{3 \mathrm{n}}$-series differ interalia in that a given member in the $\mathrm{IP}_{3 \mathrm{n}}$-series have one $\alpha-1,6$ linkage more and one $\alpha-1,4$ linkage less than the corresponding isomeric oligosaccharide in the $B_{3 n+3}$-series, e.g. $I_{12}$ versus $B_{12}$. The $-\log K_{a v}$ values recorded for the two series are given in Table IV (which also includes the $-\log K_{a v}$ value for panose) and the two straight lines of $-\log K_{a v}$ versus DP (shown in Fig. 7) have almost the same slope. For isomeric oligosaccharides in these two series there appear to be a constant increment from the $B_{3 n+3}$-series to the $I_{3 n}$-series corresponding to $\Delta-\log K_{\mathrm{av}} \sim 0.027$. This may be due to the difference in the relative number of $\alpha-1,6$ linkages as well as to the difference in the sequence in which the $\alpha-1,4$ and $a-1,6$ linkages are arranged or both. Comparison with isomeric oligosaccharides in the $M_{n}$-series and

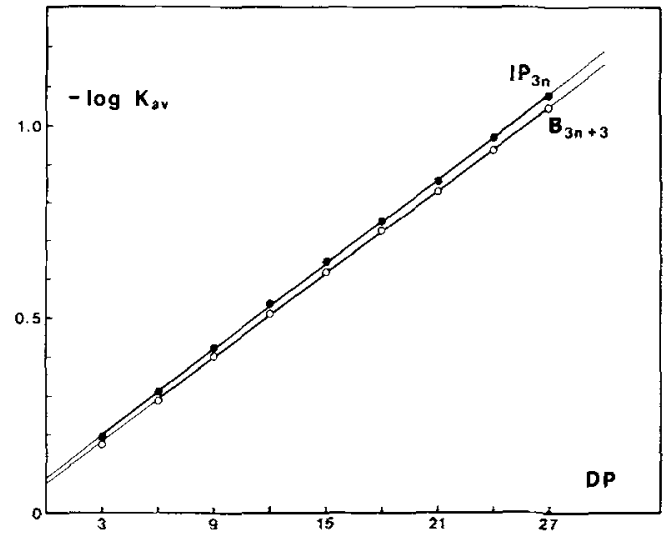

Figure 7. $-\log K_{\alpha v}$ versus DP for the $B_{3 n+3}$-and the $\mathrm{IP}_{3 \mathrm{n}}$-series.

Plot of the values of $-\log K_{a y}$ versus DP for the $B_{3 \pi+3^{-}}$ and $I_{3} P_{3 n}$-series, and the two straight lines obtained by linear regression analysis. The straight line for the $B_{3 n+3}$-series (DP 6-27) is given by: slope 0.0360 ; intersection 0.0771 ; correlation coefficient 0.9999 . The straight line for the $\mathrm{IP}_{3 \mathrm{n}}$-serjes (DP 3-27) is given by: slope 0.0366 ; intersection 0.0920 ; correlation coefficient 0.9999 .

$\mathrm{IM}_{\mathrm{n}}$-series points towards the importance of the number of $\alpha-1,6$ linkages relative to the $\alpha$ 1,4 linkages for the apparent size of these linear oligosaccharides; e. g. $\mathrm{IM}_{12}>\mathrm{IP} \mathrm{P}_{12}>\mathrm{B}_{12}>\mathrm{M}_{12}$.

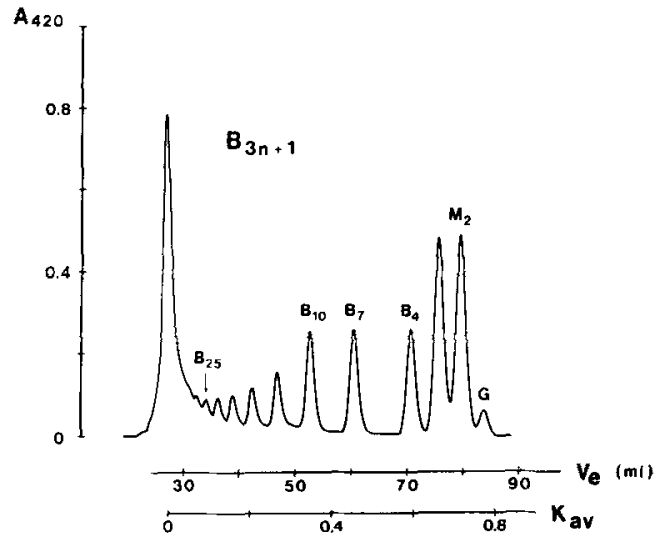

Figure 8. Elution profile of the $B_{3 n+1}$-series.

The sample has been obtained from the $B_{3 n+3}$-series (Figure 5) by action of $\beta$-amylase (EC. 3.2.1.2), whereby $B_{3 n+3} \rightarrow B_{3 n+1}+M_{2}$. In addition part of the maltotriose was hydrolysed to glucose and maltose. The peaks indicated are: glucose $(G)$, maltose $\left(M_{2}\right)$, $6^{3}$ - $a$-glucosyl-maltotriose $\quad\left(B_{4}\right), \quad 6^{3}-\alpha-\left(6^{3}-a-\right.$ glucosylmaltotriosyl)-maltotriose $\quad\left(B_{7}\right), \quad 6^{3}-\alpha-\left(6^{3}-\alpha-\left(6^{3}-\alpha-g l u-\right.\right.$ cosyl-maltotriosyl)-maltotriosyl)-maltotriose $\quad\left(B_{10}\right)$ and the higher homologue, the pentacosasaccharide $\left(B_{2 s}\right)$.

Conditions as in Figure 2. 
Table V

$-\log K_{a v}$ values for the $B_{3 n+1}-$ series, the $P_{3 n+1}$-series and the $\mathrm{IP}_{3 \pi+1}$-series and linear regression analysis of $-\mathrm{log}$ $K_{\mathrm{av}}$ versus DP.

\begin{tabular}{l|c|c|c}
\hline \multirow{2}{*}{$\mathrm{DP}$} & \multicolumn{3}{|c}{$-\log \mathrm{K}_{\mathrm{av}}$} \\
\cline { 2 - 4 } & $\mathrm{B}_{3 \mathrm{n}+1}$ & $\mathrm{P}_{3 \mathrm{n}+1}$ & $\mathrm{IP}_{3 \mathrm{n}+1}$ \\
\hline 4 & 0.220 & 0.220 & 0.226 \\
7 & 0.334 & 0.335 & 0.344 \\
10 & 0.447 & 0.449 & 0.456 \\
13 & 0.555 & - & - \\
16 & 0.666 & - & - \\
19 & 0.772 & - & - \\
22 & 0.876 & - & - \\
25 & 0.981 & - & - \\
\hline DP-range & $4-25$ & $4-10$ & $4-10$ \\
Slope & 0.0362 & & \\
Intersection & 0.0814 & & \\
Corr, coeff. & 0.9999 & & \\
\hline
\end{tabular}

Oligosaccharides having the same relative number of $\alpha-1,6$ linkages, yet differing in their sequence of $\alpha-1,4$ and $\alpha-1,6$ linkages are represented by the series of homologous oligosaccharides termed $B_{3 n+1}, P_{3 n+1}$ and $1 P_{3 n+1}$, respectively. The $-\log K_{a v}$ values for $B_{4}$, $B_{1}, B_{10}, \ldots \ldots B_{25}$, produced by the action of $\beta$-amylase on the $B_{3 n+3}$-series, have been

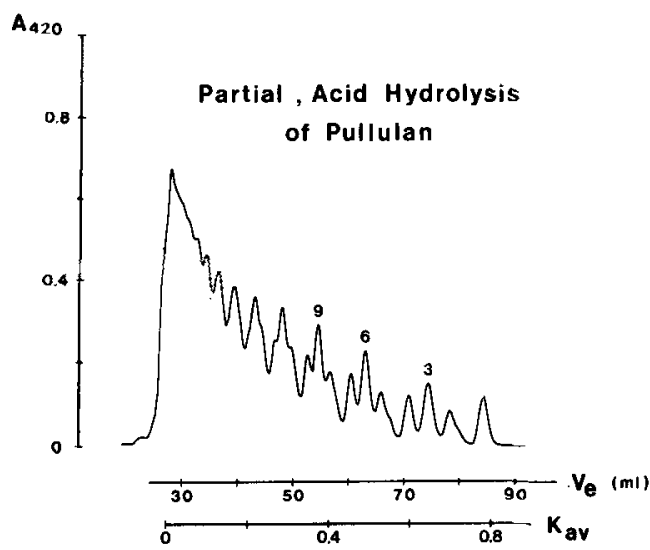

Figure 9. Elution profile of a partial, acid hydrolyzate of pullulan.

The peaks corresponding to the trisaccharides, the hexasaccharides and the nonasaccharides are indicated by their number of glucose units. (See also text).

Conditions of separation as in Figure 2.
Table VI

- $\log K_{a v}$ values for the $B_{3 n+2} 2$-series and the $\mathrm{IP}_{3 \mathrm{n}-1}$-series.

\begin{tabular}{l|c|c}
\hline \multirow{2}{*}{$\mathrm{DP}$} & \multicolumn{2}{|c}{$-\log \mathrm{K}_{\mathrm{av}}$} \\
\cline { 2 - 3 } & $\mathrm{B}_{3 \mathrm{n}+2}$ & $\mathrm{IP}_{3 \mathrm{n}-1}$ \\
\hline 5 & 0.252 & 0.272 \\
8 & 0.367 & 0.387 \\
11 & 0.478 & 0.503 \\
\hline
\end{tabular}

obtained from the elution profile of the $\mathrm{B}_{3 \mathrm{n}+1}$ series, shown in Fig. 8, and are given in Table $\mathrm{V}$. The $-\log K_{a v}$ values for the first three members of the $P_{3 n+1}$-series, $P_{4}, P_{7}$ and $P_{10}$ have been obtained from the elution profile in Fig. 9, which shows the result of a partial, acid hydrolysis of pullulan (see also Materials and Methods). Although the components designated $P_{4}, P_{7}$ and $P_{10}$ are only $60 \%$ pure,

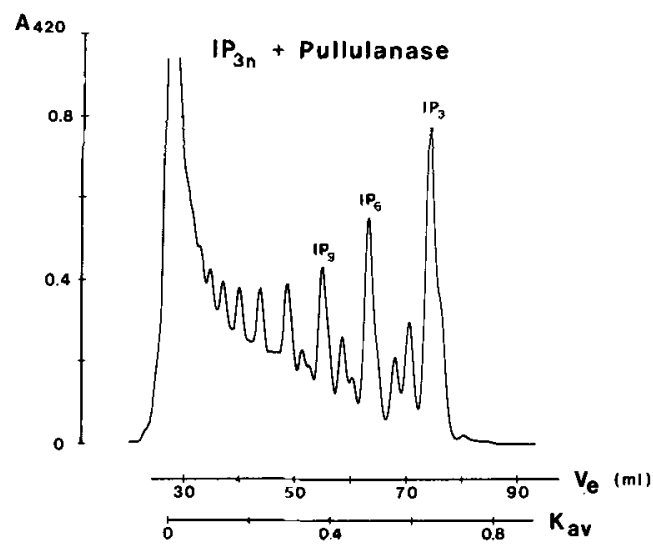

Figure 10. Elution profile of the $\mathrm{IP}_{3 n}$-series after partial hydrolysis by pullulanase.

The sample contains the $I P_{3 n}$-series as the dominant components (see Figure 6).

The point of interest, however, is that by limited action of pullulanase (EC 3.2.1.41) a relative few number of the $\alpha-1,6$ linkages in the $\mathrm{IP}_{3 n}$-series of oligosaccharides are hydrolysed. This leads to the formation of the $I_{3 n+1}$ and $B_{3 n+2}$-series of oligosaccharides, and pairs of peaks of IP $/ B_{5}, I P, / B_{8}$ and $\mathrm{IP}_{10} / \mathrm{B}_{11}$ are seen between those of the $\mathrm{IP}_{3 \mathrm{n}}$-series.

If any $\alpha-1,6$ linkage in the so formed $\mathrm{IP}_{3 n+1^{-}}$or $\mathrm{B}_{3 n+2^{-}}$ series is hydrolysed by pullulanase, a member of the $B_{3 n+3}$-series (or $M_{3}$ ) will be formed. The presence of those components are indicated by the shoulder or the skewness on the right-hand side of the peaks of the $I P_{3_{n}}$-series. 
their $-\log \mathrm{K}_{\mathrm{av}}$ values have been included in Table V. The $-\log K_{a v}$ values (Table V) for the first three members of the $\mathrm{IP}_{3 \mathrm{n}+1}$-series, $I \mathrm{P}_{4}, \mathrm{IP}_{7}$ and $\mathrm{IP}_{10}$, have been obtained from the elution profile in Fig. 10, which shows the result of a partial hydrolysis with pullulanase (pullulanolysis) of the $\mathrm{IP}_{3 \mathrm{n}}$-series of oligosaccharides. Comparison of isomeric oligosaccharides in the three series shows that although there is little difference, if any, between $B_{4}, B_{7}, B_{10}$ and $P_{4}, P_{7}, P_{10}$ there is a small yet distinct difference between $B_{4}, B_{7}, B_{10}$ and $\mathrm{IP}_{4}, \mathrm{IP}_{7}, \mathrm{IP}_{10}$ corresponding to $\Delta-\log \mathrm{K}_{\mathrm{av}} \sim$ 0.008 . This shows that the sequence in which a given number of $\alpha-1,4$ and $\alpha-1,6$ linkages are arranged may influence the apparent size of the molecules in solution; e.g. $\mathrm{IP}_{4}$ (6-a-maltotriosylglucose $)>\mathrm{B}_{4}\left(6^{3}-\alpha\right.$-glucosyl-maltotriose $)$.

Isomeric oligosaccharides which differ in their relative number of $\alpha-1,6$ linkages as well as in their linear sequence have been represented by the $\mathrm{B}_{3 \mathrm{n}+3}$-series and the $\mathrm{IP}_{3 \mathrm{n}}$-series, having $\Delta-\log \mathrm{K}_{\mathrm{av}} \sim 0.027$. In addition the first three members of the $\mathrm{B}_{3 \mathrm{n}+2}$-series and the $\mathrm{IP}_{3 \mathrm{n}-1^{-}}$ series have been examined. The - $\log K_{a v}$ values for $B_{5}, B_{8}$ and $B_{11}$ were obtained from the elution profile in Fig. 10 and the $-\log K_{a v}$ values for $I P_{5}, I_{8}$ and $I P_{11}$ were obtained from the elution profile in Fig. 9. The results are given in Table VI. The results in Table VI reveal a distinct difference between the two series of oligosaccharides corresponding to $\Delta-\log K_{\mathrm{av}} \sim$ 0.022 , in accordance with $\mathrm{IP}_{5}>\mathrm{B}_{5} ; \mathrm{IP}_{8}>\mathrm{B}_{8}$; etc.

\subsection{Cyclic, $\alpha-1,4$ linked oligosaccharides :}

$\alpha$-Schardinger dextrin (cyclomaltohexaose) and $\beta$-Schardinger dextrin (cyclomaltoheptaose) have been analysed as pure samples and as a combined product using Bio-Gel P-2 as well as Bio-Gel P-4. The elution profile in Fig 11 shows the separation of $\alpha$-Schardinger dextrin from $\beta$-Schardinger dextrin using Bio-Gel P-4, and the corresponding $-\log K_{\mathrm{av}}$ values are given in Table VII. Superimposed on the recorder trace (elution profile) of the Schardinger dextrins is that of the malto-oligosaccharides. The observed positions in the elution profile show that the apparent size of these cyclic, $a-1,4$

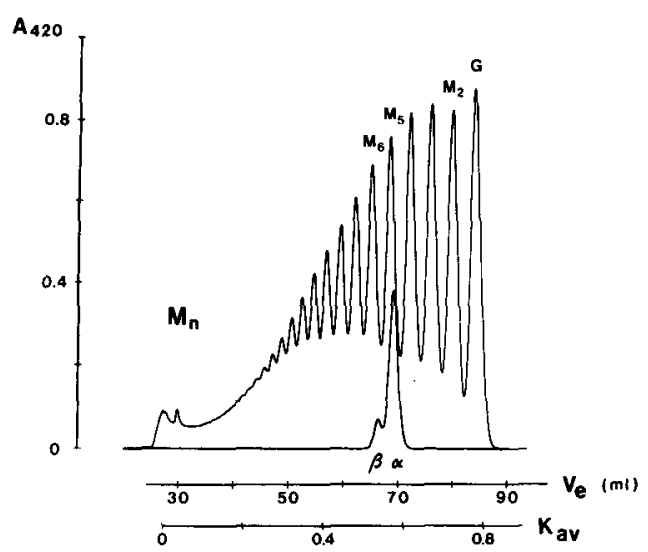

Figure 11. Elution profile of the Schardinger dextrins, superimposed on that of the $\mathbf{M}_{\mathbf{n}}$-series.

The sample (Pierce, $\alpha$-Schardinger dextrin) contained about $80 \% \alpha$-Schardinger ( $\alpha$ ) and about $20 \% \quad \beta$ Schardinger dextrin $(\beta)$. This elution profile is superimposed on that of the malto-oligosaccharides (Figure 2), illustrating the size relations mentioned in the text.

Conditions of separation as in Figure 2.

\section{Table VII}

$-\log K_{a y}$ values for the cyclic, $a-1,4$ linked oligosaccharides (Schardinger dextrins).

\begin{tabular}{l|c}
\hline & $-\log \mathrm{K}_{\mathrm{av}}$ \\
\cline { 2 - 2 } & 0.241 \\
$\beta-$ Schardinger dextrin & 0.271 \\
\hline
\end{tabular}

linked oligosaccharides is considerably smaller than that of the corresponding linear, $\alpha-1,4$ linked oligosaccharides, similarly composed of glucose. The difference between $\alpha$-Schardinger dextrin $(\alpha)$ and maltohexaose $\left(M_{6}\right)$ and between $\beta$-Schardinger dextrin $(\beta)$ and maltoheptaose $\left(\mathrm{M}_{7}\right)$ corresponds to $\Delta-\log \mathrm{K}_{\mathrm{av}} \sim-0.042$ and -0.047 respectively. Accordingly: $M_{7}>M_{6}>\beta>$ $\mathbf{M}_{3}>\alpha>\mathbf{M}_{4}$. Thus, using the malto-oligosaccharides as a reference the position in the elution profile of the $\alpha$ - and $\beta$-Schardinger dextrins corresponds to 4.84 and 5.67 glucose units in the $M_{n}$-series. 
3.5 Oligosaccharides in acid and enzymic hydrolyzates of starch:

Starch conversion products available in quantity as a product of commerce consist of oligosaccharides composed of glucose linked either $\alpha-1,4$ only (malto-oligosaccharides) or $\alpha-1,4: \alpha$ 1,6 (in some cases in a linear sequence but more frequently in singly- and multiply-branched structures). As an example of an acid hydrolyzate of starch a glucose syrup from wheat starch has been analysed. The elution profile is shown in Fig. 12 and the corresponding - $\log \mathrm{K}_{\mathrm{av}}$ values are given in Table VIIl. The straight line obtained by linear regression analysis is almost identical with that of the malto-oligosaccharides used as reference.

Furthermore the oligosaccharides in beer have been analysed. They originate mainly from the enzymic conversion of barley malt starch (by means of $\alpha$-amylase and $\beta$-amylase) from which glucose, maltose and maltotriose have been removed by fermentation. The elution profile is

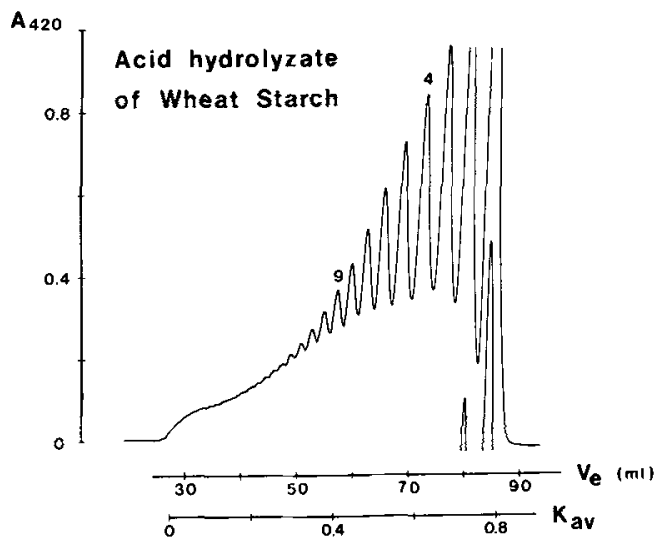

Figure 12. Elution profile of a partial, acid hydrolyzate of wheat starch.

The sample is a commercial glucose syrup. The peak to the very right, corresponding to glucose, has absorbance $=1.50$, and the next peak, corresponding to the disaccharides (mainly maltose), has absorbance $=1.11$. Recordings of absorbances above $1(\mathrm{~A}=1-2)$ are possible since the instrument then automatically subtracts the equivalent of one absorbance unit. The higher oligomers are all below absorbance 1 . The peaks corresponding to the tetrasaccharides and the nonasaccharides are indicated by their number of glucose units.

Conditions of separation as in Figure 2. shown in Fig. 13 and the corresponding $-\log \mathrm{K}_{\mathrm{av}}$ values are given in Table VIII. Linear regression analysis gives a straight line which has been used to determine the DP of higher molecular weight dextrins less well resolved (9). Comparison of the $-\log \mathrm{K}_{\mathrm{av}}$ values for the dextrins of DP 5-16 in beer with those for the isomeric malto-oligosaccharides shows that for DP 5-8 the $-\log K_{a v}$ values are identical, for DP 9-11 the beer dextrins have slightly smaller $-\log \mathrm{K}_{\mathrm{av}}$ values and for DP 12-15 somewhat smaller -log $\mathbf{K}_{\mathrm{av}}$ values corresponding to $\Delta-\log \mathrm{K}_{\mathrm{av}} \sim$ (0.008-0.017) compared to the linear, exclusively $\alpha-1,4$ linked malto-oligosaccharides.

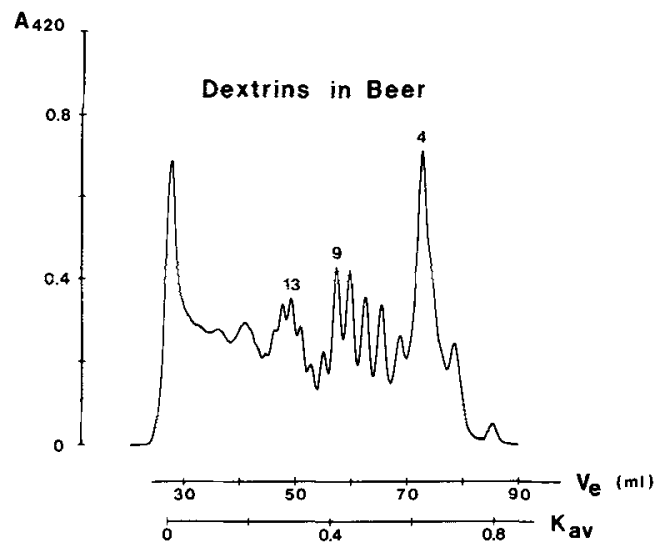

Figure 13. Elution profile of the oligosaccharides in beer.

A bottle of Danish Lager was taken from the production line. Of this beer $15 \mu$ was used to obtain the elution profile shown above. The peak to the very right corresponds to the monosaccharides, which are mainly arabinose and xylose (the $-\log \mathrm{K}_{\mathrm{av}}$ value for these pentoses (Table VIII) is somewhat smaller than that of the hexose, glucose). The next peak corresponds to isomaltose, which - in contrast to maltose - is not fermented by most brewer's yeast (compare also the $-\log \mathrm{K}_{\mathrm{av}}$ value of DP 2 in beer (Table VIII), with that of isomaltose from Table III). The trisaccharides has not been resolved into a separate peak, probably due to the presence of maltotriose as well as panose and isopanose (Bathgate, 1969). The tetrasaccharides (4) consists mainly (about 70\%) of maltotetraose, the remainder being $6^{3}$ - $\alpha$-glucosyl-maltotriose $=B_{4}$. The oligosaccharides of DP 5-10 are essentially singlybranched, those of DP 11-16 essentially doubly-branched, etc. (See also ENEvoldSEN \& SChMidt (9)).

Conditions of separation as in Figure 2. 
$-\log \mathrm{K}_{\mathrm{av}}$ values for the oligosaccharides from acid hydrolysis of wheat starch and from beer, and linear regression analysis of $-\log K_{a v} v e r s u s$ DP. The malto-oligosaccharides (from Table II) have been included for comparison.

\begin{tabular}{l|c|c|c}
\hline \multirow{2}{*}{ DP } & \multicolumn{3}{c}{ - log $\mathrm{K}_{\mathrm{av}}$} \\
\cline { 2 - 4 } & $\begin{array}{c}\text { Wheat } \\
\text { Starch } \\
\text { Hydrolyzate }\end{array}$ & Beer & $\mathrm{M}_{\mathrm{n}}$ \\
\hline 1 & $(0.109)$ & $(0.101)$ & \\
2 & 0.141 & $0.155)$ & $(0.109)$ \\
3 & 0.175 & - & 0.141 \\
4 & 0.210 & $(0.209)$ & 0.174 \\
5 & 0.248 & 0.247 & 0.210 \\
6 & 0.283 & 0.283 & 0.247 \\
7 & 0.320 & 0.317 & 0.283 \\
8 & 0.354 & 0.353 & 0.318 \\
9 & 0.389 & 0.385 & 0.353 \\
10 & 0.424 & 0.420 & 0.389 \\
11 & 0.460 & 0.455 & 0.424 \\
12 & 0.492 & 0.485 & 0.459 \\
13 & 0.526 & 0.519 & 0.493 \\
14 & - & 0.549 & 0.527 \\
15 & - & 0.579 & 0.562 \\
16 & - & 0.620 & 0.596 \\
\hline DP-range & $2-13$ & $5-16$ & - \\
Slope & 0.0352 & 0.0334 & $2-15$ \\
Intersection & 0.0711 & 0.0835 & 0.0351 \\
Correlation coefficient & 0.9999 & 0.9997 & 0.0710 \\
\hline & & & 1.0000 \\
\hline
\end{tabular}

\section{DISCUSSION}

The present study concerns the gel filtration chromatographic properties of a variety of structurally related oligosaccharides composed of glucose and linked $\alpha-1,4$ and/or $\alpha-1,6$. Thus the quantitative aspect of gel filtration chromatography of oligosaccharides will not be discussed in the present context. Furthermore the resolution of neighbouring components which depends on several factors (e.g. type of gel, the batch in question, the particle size distribution of the gel and the temperature employed) will not be discussed in any detail. We have preferably used polyacrylamide gels (Bio-Gel P-2, Bio-Gel P-4, etc.) to dextran gels (Sephadex G-10, Sephadex G-15, etc.) inter alia since adsorption chromatography of Schardinger dextrins occur on Sephadex G-15, whereas on Bio-Gel P-2 a normal molecular sieving process seems to take place (4). We have used de-ionized water as solvent. This facilitates the subsequent quantitative recording of the eluate either by means of a refractive index monitor or as used in this study by means of chemical detection using orcinolsulphuric acid. All separations have been performed at a constant temperature of $65^{\circ} \mathrm{C}$. This prevents microbiological contaminations to which the oligosaccharides are sensitive and in addition improves the separation characteristics of the column $(17,6)$.

The position of a given oligosaccharide in the elution profile is accessible as the appropriate distance on the recorder trace, and may readily be expressed in terms of its retention time or its elution volume, $\mathrm{V}_{\mathrm{e}}$. In order to eliminate the column dimensions various transformations as listed by DETERMANN (8) are frequently used. 
These include $V_{e} / V_{0}, K_{a v}$ and $K_{d}$. Analysis of the gel filtration chromatographic behaviour of the series of homologous malto-oligosaccharides including glucose has been performed by DELLWEG and coworkers $(11,6)$. They find that a plot of $-\log \mathrm{K}_{\mathrm{d}}$ versus DP gives a straight line (6) (DP 1-7), whereas a plot of $\mathrm{V}_{\mathrm{e}} / \mathrm{V}_{\mathrm{o}}$ versus $\log \mathrm{MW}$ does not (11) (DP 1-13). Since $K_{a v}$ is readily determined from $V_{o}, V_{e}$ and $V_{t}$, whereas $K_{d}$ requires the additional estimation of the volume, $V_{m}$, occupied by the gel matrix, we have preferably used $K_{a v}$ rather than $K_{d}$. Since $K_{a v}=$ constant $\times K_{d}$, a straight line relationship of $-\log K_{d}$ versus DP will give a straight line relationship of $-\log \mathrm{K}_{\mathrm{av}}$ versus DP, and the two lines will have identical slopes.

In addition to the oligosaccharides present in starch conversion products we have determined the $\mathrm{K}_{\mathrm{av}}$ values of 68 distinct oligosaccharides composed of glucose and linked $\alpha-1,4$ and/or $\alpha-1,6$. They comprise 14 linear, $\alpha-1,4$ oligosaccharides (maltose-maltopentadecaose), 14 linear, $\alpha-1,6$ oligosaccharides (isomaltoseisomaltopentadecaose), 38 linear, $\alpha-1,4: \alpha 1,6$ oligosaccharides (DP-range 3-27) and 2 cyclic, $\alpha-1,4$ linked oligosaccharides (DP 6-7). In the following we will discuss the position of these oligosaccharides in the elution profile.

\subsection{Comparison of members within a series of homologous oligosaccharides:}

Linear regression analysis of each of the various series of homologous oligosaccharides included in this study has shown that the experimental values give an exceedingly good fit to a straight line corresponding to $-\log \mathrm{K}_{\mathrm{av}}$ versus DP, as indicated by the correlation coefficients 0.9998 1.0000. (See also Fig. 4 and Fig. 7). Even for the series of oligosaccharides derived from starch and which contain several isomers, correlation coefficients of $0.9997-0.9999$ are noticed. Nevertheless it should be noted that a more close examination shows that there is a minute, yet systematic deviation from the apparent straight line for all of the series of homologous oligosaccharides in as much that the $\Delta-\log K_{a v}$ value from one member to the next member in its series decreases with increasing DP. For the $M_{n}$-series the difference between the $-\log K_{a v}$ values for $M_{3}$ and $M_{4}$ is 0.036 whereas the difference between $M_{14}$ and $M_{15}$ is 0.034 . For the $\mathrm{IP}_{3 \mathrm{n}}$-series where the increments corresponds to 3 glucose residues the difference between the $-\log \mathrm{K}_{\mathrm{av}}$ values for $\mathrm{IP}_{3}$ and $\mathrm{IP}_{6}$ is 0.117 whereas the difference between $\mathrm{IP}_{24}$ and $\mathrm{IP}_{27}$ is 0.106 .

Of the nine series of homologous oligosaccharides which may be derived from pullulan, we have no representative of the $\mathrm{P}_{3 \mathrm{n}+2}$-series and one member only of the $\mathrm{P}_{3 \mathrm{n}}$ series i.e. the trisaccharide panose. The other seven series are represented by three up to nine members. From these seven series it is possible to select 30 pairs of successive members within series of homologous, $\alpha-1,4: \alpha-1,6$ linked, linear oligosaccharides. The average increment in the $-\log K_{\mathrm{av}}$ value for these 30 pairs is 0.111 corresponding to the addition of 3 glucose residues, two of which are $\alpha-1,4$ linked, one $\alpha$ 1,6 linked.

With respect to the malto-oligosaccharides and the isomalto-oligosaccharides the straight line relationship of $-\log \mathrm{K}_{\mathrm{av}}$ versus DP reveals that the average increment in the $-\log K_{a v}$ value corresponds to:

$\Delta$ - $\log \mathrm{K}_{\mathrm{av}}=0.035$ per $\alpha-1,4$ linked glucose residue

$\Delta-\log \mathrm{K}_{\mathrm{av}}=0.045$ per $\alpha-1,6$ linked glucose residue.

\subsection{Comparison of isomeric oligosaccharides:}

The oligosaccharides under study are composed of glucose only (i.e. they do not differ in their constituent monosaccharide unit). Furthermore, only two types of glucosidic linkages are involved, the $\alpha-1,4$ and the $\alpha-1,6$ glucosidic linkage. We will distinguish between two types of isomeric oligosaccharides.

i) isomeric oligosaccharides which differ in the relative number of $\alpha-1,6$ linkages (and accordingly in the relative number of $\alpha-1,4$ linkages). These isomeric oligosaccharides differ also in the sequence of $\alpha-1,4$ and $\alpha-1,6$ linkages.

ii) isomeric oligosaccharides which have the same relative number of $\alpha-1,6$ linkages but differ in the sequence in which the $\alpha-1,4$ and $\alpha-1,6$ linkages are arranged.

Comparison of the $-\log \mathrm{K}_{\mathrm{av}}$ values for the linear, $\alpha-1,4$ and/or $\alpha-1,6$ linked oligo- 
saccharides (Tables II-VI) shows that isomers which differ in the relative number of $\alpha-1,6$ linkages (e.g. $\mathbf{M}_{9}, \mathbf{B}_{9}, \mathrm{IP}_{9}, \mathrm{IM}_{\mathbf{9}}$ ) have $-\log \mathrm{K}_{\mathrm{av}}$ values that increase with the number of $\alpha-1,6$ linkages. However, part of the differences observed may be due to a difference in the sequence of $\alpha-1,4$ and $\alpha-1,6$ linkages beyond that necessitated by the replacement of $\alpha-1,4$ linkages by $\alpha-1,6$ linkages. This effect can to some extent be observed separately, since comparison of the $-\log K_{a v}$ values for isomers with the same relative number of $\alpha=1,6$ linkages (e.g. $\left.B_{10}, P_{10}, I P_{10}\right)$ shows that the sequential arrangement of the $\alpha-1,4$ and $\alpha-1,6$ linkages in these linear oligosaccharides is also of importance.

\subsection{Correlation between the structure of} oligosaccharides and their $-\log K_{a v}$ values:

We will first consider a possible correlation between the structure of the linear, $\alpha-1,4, \alpha-1,4$ : $\alpha-1,6$ and $\alpha-1,6$ linked oligosaccharides and their position in the elution profile expressed by their $-\log \mathrm{K}_{\mathrm{av}}$ values. We will consider eleven structurally related series of homologous oligosaccharides composed of glucose in a linear sequence. These are the $M_{n}$-series (exclusively $\alpha-1,4$ linked), the nine series derived from pullulan $\left(\alpha-1,4: \alpha-1,6\right.$ linked) and the $\mathrm{IM}_{\mathrm{n}}$ series (exclusively $\alpha-1,6$ linked). If we proceed from the monosaccharide, glucose, addition of $\alpha-1,4$ or $\alpha-1,6$ linked glucose residues leads to the disaccharides, maltose and isomaltose. Subsequent addition of either an $\alpha-1,4$ or an $\alpha-1,6$ linked glucose residue to the non-reducing end leads to the four linear trisaccharides, maltotriose, panose, isopanose and isomaltotriose. ${ }^{\circ}$ The structure of these mono-, di- and trisaccharides and their $-\log K_{a v}$ values are shown in Fig. 14. From maltotriose and isomaltotriose we get the higher homologues of the $M_{n}$ - and $I_{n}-$ series by adding $a-1,4$ and $\alpha$ 1,6 linked glucose residues, respectively. As already mentioned for these two series of homologous oligosaccharides the average increment per $a-1,4$ linked and $a-1,6$ linked glucose residue corresponds to $\Delta-\log \mathrm{K}_{\mathrm{av}}=$
0.035 and 0.045 respectively. As indicated in Fig. 14 (see also Fig. 1) the trisaccharides, maltotriose, panose and isopanose, represent the reducing chain-end triplets of the B-, P-and IP-series of oligosaccharides. Addition of glucose residues either $\alpha-1,4$ or $\alpha-1,6$ to $M_{3}, P_{3}$ and $\mathrm{IP}_{3}$ in the sequence determined by the structure of pullulan then leads to the three types of oligosaccharides. Each type represents a series of non-homologous oligosaccharides (e.g. $B_{4}, B_{5}, B_{6}$, etc.). It seems, however, possible to correlate the observed $-\log K_{a v}$ values with the structure of these three types of oligosaccharides. If we accept the experimental $-\log K_{a v}$ values for $M_{3}, P_{3}$ and $I P_{3}$ we can to some extent account for the $-\log K_{a v}$ values for higher oligomers, merely by adding up for the additional $\alpha-1,4$ and $\alpha-1,6$ linked glucose residues, using the average increments in -log $\mathrm{K}_{\mathrm{av}}$ observed for the $\mathrm{M}_{\mathrm{n}}$ - and $\mathrm{IM}_{\mathrm{n}}$-series. As an example we will calculate the $-\log K_{a y}$ values for the heptasaccharides, $\mathrm{B}_{7}, \mathrm{P}_{7}$ and $\mathrm{IP}_{7}$ :

$\mathrm{B}_{7}=\mathrm{M}_{3}+2 \alpha-1,4 \mathrm{G}+2 \alpha-1,6 \mathrm{G}=0.334$

$P_{7}=P_{3}+3 \alpha-1,4 G+1 \alpha-1,6 G=0.336$

$\mathrm{IP}_{7}=\mathrm{IP}_{3}+3 \alpha-1,4 \mathrm{G}+1 \alpha-1,6 \mathrm{G}=0.344$.

These values are in close agreement with the observed $-\log \mathrm{K}_{\mathrm{av}}$ values. The above correlation appears to be valid for the pullulan derived oligosaccharides of DP 4 - DP 10 but gives too high estimates above DP 10. Some of the points discussed so far have been illustrated in Fig. 15. Finally it may be of interest to note that the nine series of homologous oligosaccharides derived from pullulan may be classified into 3 groups which reflect their relative number of $\alpha$ 1,6 linkages. Thus all members of the $B_{3 n+1}$-, $P_{3 n+1}$ and $I P_{3 n+1}$-series have one $\alpha-1,6$ linkage per two $\alpha-1,4$ linkages corresponding to $33.3 \%$ $\alpha-1,6$ linkages. In contrast all members of the $\mathrm{P}_{3 \mathrm{n}^{-}}, \mathrm{IP}_{3 \mathrm{n}^{-}}$and $\mathrm{IP}_{3 \mathrm{n}-1}$-series have more than $33.3 \% a-1,6$ linkages whereas those of the $P_{3 n+2^{-}}$, $\mathbf{B}_{3 n+2}$ and the $\mathbf{B}_{3 n+3}$-series have less than $33.3 \%$ a-1,6 linkages.

If we turn to the branched, $\alpha-1,4: \alpha-1,6$ linked oligosaccharides derived from amylopectin by acid or enzymic hydrolysis, it is somewhat more

- Addition of an $a-1,4$ or an $a-1,6$ linked glucose residue to the glucose unit of the reducing end of isomaltose or maltose leads to the trisaccharide, 4,6-di- $\alpha$-glucosyl-glucose ( $6^{1}-\alpha$-glucosyl-maltose $)$ which typifies the branch point(s) in branched dextrins derived from amylopectin and glycogen. 
F. SCHMidT \& B. S. ENEvoldsen: Gel Filtration Chromatography of oligosaccharides

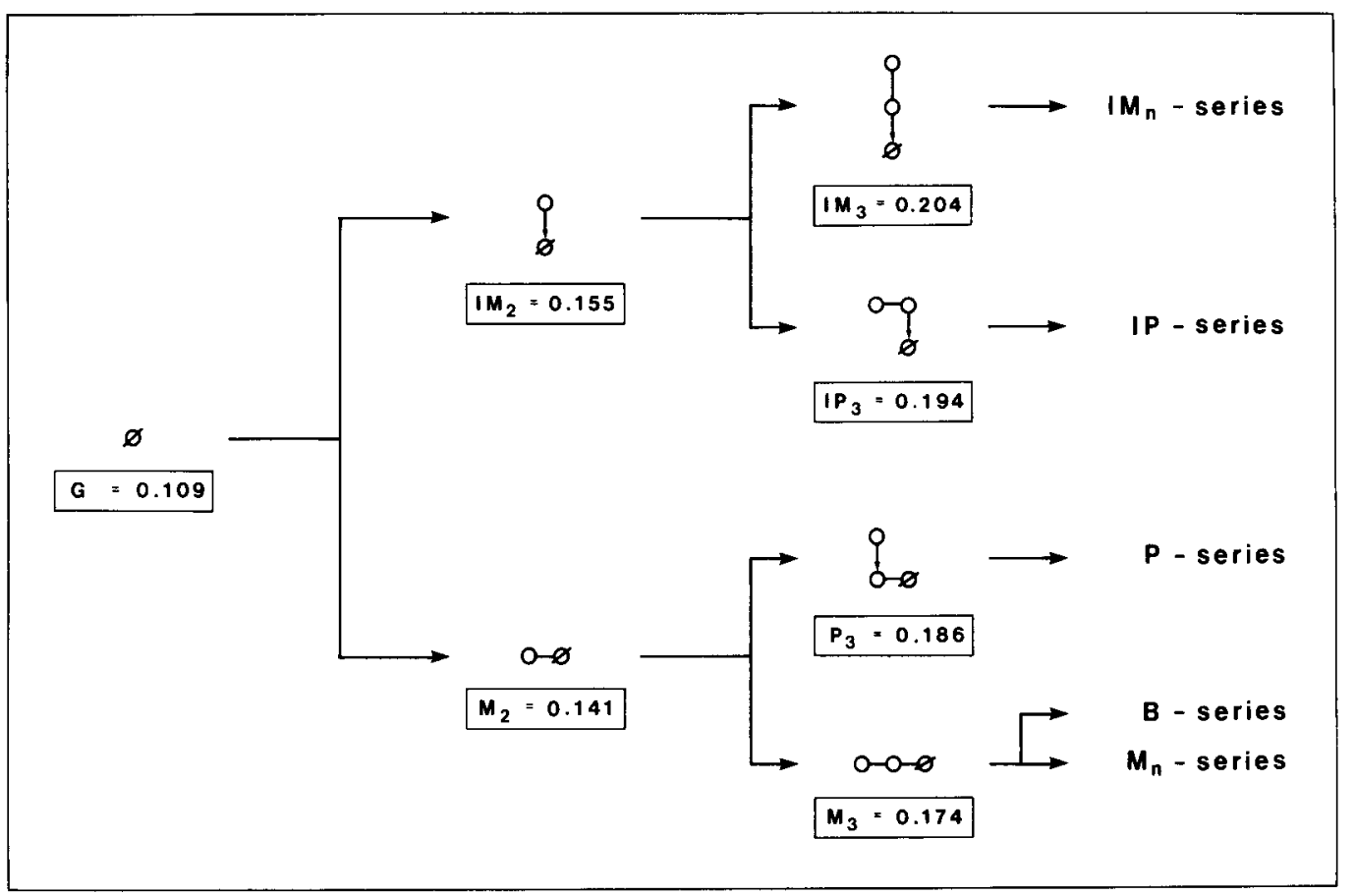

Figure 14. Schematic representation of $\alpha-1,4$ and/or $\alpha-1,6$ linked di- and trisaccharides derived from the monosaccharide, glucose, and the observed - $\log K_{\mathrm{av}}$ values for these oligosaccharides and for glucose. (See also text). For symbols and abbreviations see legend to Figure 1.

$I M_{7}=0.389 \quad \frac{\alpha-1,6}{0.045} \quad I M_{8}=0.434 \quad \frac{\alpha-1,6}{0.045} \quad 1 M_{9}=0.479 \quad \frac{\alpha-1,6}{0.043} \quad 1 M_{10}=0.522$
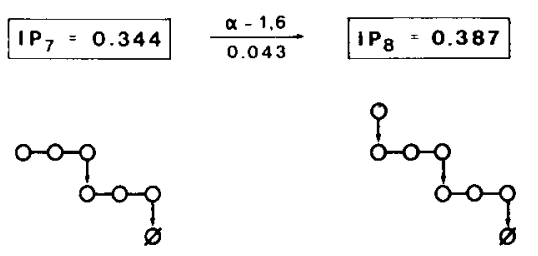

$\frac{\alpha-1,4}{0.038}$

$$
I P_{g}=0.425
$$

$\frac{\alpha-1,4}{0.031}$
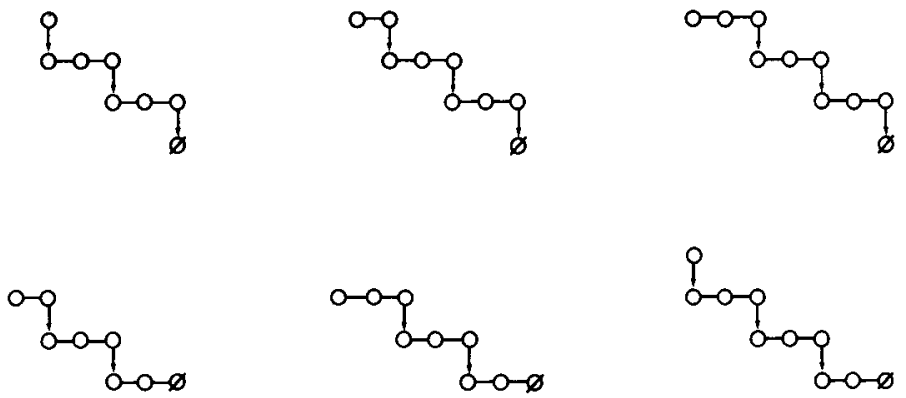

$\frac{\alpha-1.4}{0.033}$

$B_{8}=0.367$

$\frac{\alpha-1,4}{0.035}$

$B_{9}=0.402$

$\frac{a-1,6}{0.045}$

$B_{10}=0.447$

$M_{7}=0.318$

$\frac{\alpha-1.4}{0.035} \quad M_{8}=0.353$

$\frac{\alpha-1,4}{0.036} \quad M_{9}=0.389$

$\frac{\alpha-1,4}{0.035}$

$M_{10}=0.424$

106

Carlsberg Res. Commune. Vol. 41, No 2, 1976 
difficult to correlate the observed $-\log \mathrm{K}_{\mathrm{av}}$ values with the structure of these oligosaccharides. Taken at their face value the observed $-\log \mathrm{K}_{\mathrm{av}}$ values are either identical with or somewhat smaller than those for their isomeric malto-oligosaccharides (exclusively $a$ 1,4 linked). In a series of studies we have examined the structure of the singly- and multiply-branched dextrins in beer (see also ENEVOLDSEN \& SCHMIDT (9)). The two singlybranched heptasaccharides shown in Fig. 16 have been isolated from beer as a mixture and their $-\log K_{\mathrm{av}}$ value found to be identical with that for $\mathbf{M}_{7}$. Thus it appears that although we would expect an increase in the - $\log K_{a v}$ value due to the presence of an $\alpha-1,6$ linkage, this may somehow be counterbalanced by the branched structure of these heptasaccharides. If we take the tridecasaccharides as an example of the doubly-branched dextrins in beer, we reckon that they represent structures with more dense branching (about one $\alpha-1,6$ linkage per six glucose units) than those encountered in the acid hydrolyzate of wheat starch. In Fig. 16 are shown the two main types of doubly-branched

1 Figure 15. The diagram shows the observed $-\log K_{a v}$ values for successive members in the two series of homologous oligosaccharides, the malto-oligosaccharides (exclusively $a-1,4$ linked) and the isomalto-oligosaccharides (exclusively $a-1,6$ linked) as well as for successive members in two non-homologous series: $B_{1}, B_{8}, B_{9}, B_{10}$ and $I P_{,}, I P_{8}, I P_{9}, I P_{10}$. Comparison of isomeric oligosaccharides reveals characteristic differences which can be related to the relative number of $a-1,6$ linkages (e.g. $\mathrm{IM}_{9}>\mathrm{IP},>\mathrm{B}_{9}$ $>M_{9}$ ) as well as to the sequence in which the $a-1,4$ and $a-1,6$ linkages are arranged $\left(B\right.$, compared to $I P_{7}$; $B_{10}$ compared to $\left.I P_{10}\right)$. Please observe that the hepta-, octa- and nonasaccharides: $I_{7}, I_{8}$ and $M_{9}$ have almost identical $-\log \mathrm{K}_{\mathrm{av}}$ values and thus will occupy the same position in the elution profile. Symbols as in Figure 1.

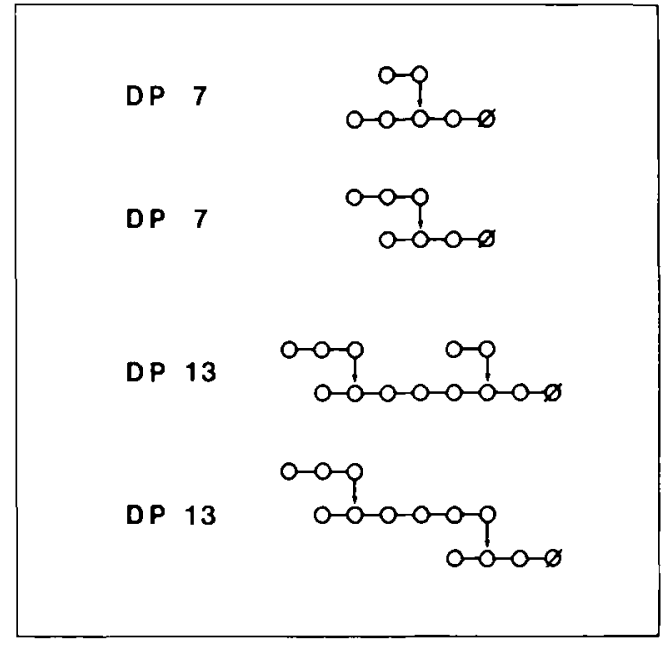

Figure 16. Singly-branched heptasaccharides and probable representatives of doubly-branched tridecasaccharides in beer (see also text). Symbols as in Figure 1.

dextrins (9) present in about equal amounts in beer. The fine structure of these dextrins of DP 13 is hypothetical yet probably representative of the various isomeric tridecasaccharides in beer. The observed $-\log K_{\mathrm{av}}$ value is significantly smaller than that for the isomeric $\mathrm{M}_{13}$. Thus the branched nature of these dextrins tends to result in $-\log \mathrm{K}_{\mathrm{av}}$ values smaller than those for the isomeric linear, malto-oligosaccharides in spite of the presence of one or more $a-1,6$ linkages.

\subsection{Comments on the size or whydrodynamic volume " of oligosaccharides in solution: \\ If we assume that the position in the elution profile of a given oligosaccharide reflects its size in solution, gel filtration chromatography offers a means of determining the size or whydrodynamic volume" of oligosaccharides, at least relative to other oligosaccharides. ${ }^{\circ}$ We have used the malto-oligosaccharides as the}

\footnotetext{
${ }^{\circ} \mathrm{Gel}$ filtration chromatography is generally recognized as a method which separates molecules according to their size in solution. However, this is difficult to verify since the size of such molecules may be unknown and other factors than whe hydrodynamic volumen may influence the position of a given molecule in the elution profile. It is known that the Schardinger dextrins on Sephadex G-15 are retarded well beyond their expected elution volumes appearing after glucose in the elution profile (4). Deviations from the expected gel filtration chromatographic behaviour may also occur using polyacrylamide gels. DeLLwEG et al. (7) have reported that 2deoxy-glucose is eluted between glucose and maltose on Bio-Gel P-2 and we have recently found that inter alia amethyl-glucoside is eluted between maltose and maltotriose on Bio-Gel P-4.
} 


\section{Table IX}

Size of oligosaccharides composed of glucose with $\alpha-1,4$ and/or $\alpha-1,6$ linkages.

The size or whydrodynamic volume of these oligosaccharides has been determined by gel filtration chromatography on $\mathrm{Bio}-\mathrm{Gel} \mathrm{P}-4$ in water at $65^{\circ} \mathrm{C}$ relative to the malto-oligosaccharides.

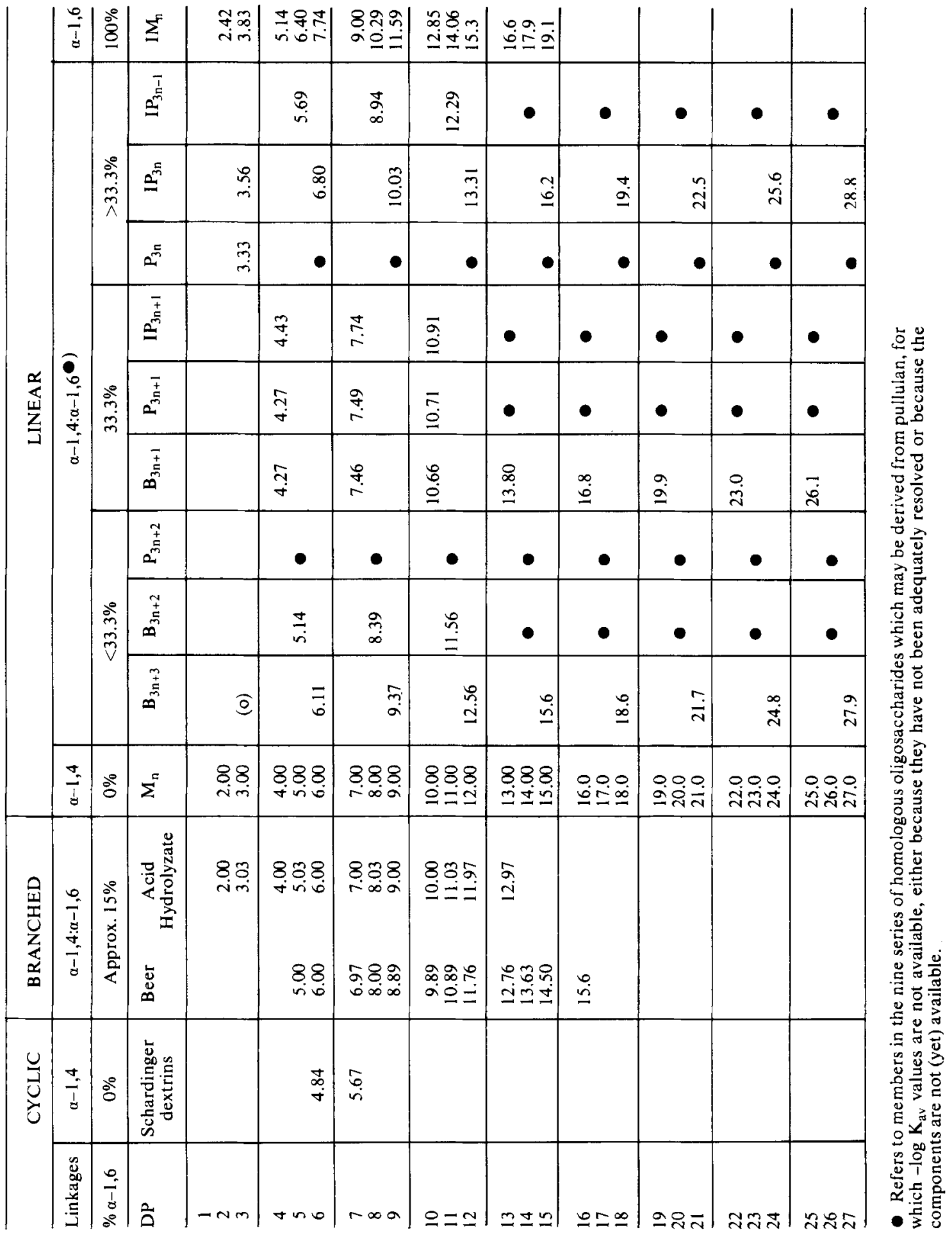


common reference for the various oligosaccharides included in this study. Based on the $-\log \mathrm{K}_{\mathrm{av}}$ values for the various oligosaccharides we have calculated their size relative to the malto-oligosaccharides. With respect to oligosaccharides for which the observed $-\log K_{a v}$ values fall within those for maltose and maltopentadecaose we have used the observed $-\log \mathrm{K}_{\mathrm{av}}$ value for the oligosaccharides in question as well for the maltooligosaccharides. For oligosaccharides of the $B_{3 n+3^{-}}, B_{3 n+1^{-}}$and $I_{3 n^{-}}$-series for which the observed $-\log K_{a v}$ values exceed that for $M_{13}$, their relative size has been determined using the straight line relationship of $-\log K_{\mathrm{av}}$ versus DP for these series as well as for the $M_{n}$-series. The values for the relative size of the various oligosaccharides are given in Table IX.

The $\alpha$ - and $\beta$-Schardinger dextrins have molecular weights $(\alpha-S D \sim 972, \beta-S D \sim 1134)$ only slightly smaller than the corresponding malto-oligosaccharides $\left(M_{6} \sim 990, M_{7} \sim 1152\right)$ yet they are apparently more than one $, a-1,4$ linked glucose unit" smaller than their almost isomeric malto-oligosaccharides. This seems compatible with their cyclic structure, yet may not always be taken into account, when Schardinger dextrins - because they are more readily available than most oligosaccharides of similar molecular weight - are used as markers and for calibration purposes.

The oligosaccharides present in acid and enzymic hydrolyzates of starch consist of malto-oligosaccharides and oligosaccharides with one or more $\alpha-1,6$ linkages generally of a branched structure. These oligosaccharides appear to be of the same size or slightly smaller than the corresponding malto-oligosaccharides. Yet it is of interest to notice that structural entities corresponding to the pullulan derived linear, $\alpha-1,4: \alpha-1,6$ linked oligosaccharides may also be present in amylopectin. Thus $B_{4}=6^{3}-\alpha$-glucosyl-maltotriose and $B_{3}=6^{3}$ $a$-maltosyl-maltotriose are present in beer. Furthermore UmeKı \& Yamamoto (18) have obtained $B,=6^{3}-\alpha-\left(6^{3}-\alpha-\right.$ glucosyl-maltotriosyl $)$ maltotriose among the oligosaccharides formed by the action of saccharifying $a$-amylase of Bacillus subtilis on waxy rice starch and more recently (19) have identified the next higher homologue, $B_{10}$, among the reaction products from starch. According to our findings $B_{10}$ is about two thirds of a glucose unit larger than maltodecaose and the branched, $a-1,4: a-1,6$ linked decasaccharides encountered in beer. Depending on the fine structure of amylopectin and the specificity of the various $a$-amylases towards the $a-1,4$ linkages in the proximity of the branch point(s), a variety of branched dextrins are formed. It would be of interest to know whether the specificity of these $\alpha$-amylases also includes selectivity according to the size of the resultant oligosaccharides.

Moreover, the relative size of 38 of the linear, $\alpha-1,4: \alpha-1,6$ linked oligosaccharides derived from pullulan has been listed in Table IX as well as the size of the 14 isomalto-oligosaccharides, $\mathrm{IM}_{2}-\mathrm{IM}_{15}$, the latter, isomaltopentadecaose, being about four $a-1,4$ linked glucose units* larger than the isomeric maltopentadecaose.

The present study has comprised oligosaccharides present in starch conversion products as well as several series of homologous oligosaccharides similarly composed of glucose and with $\alpha-1,4$ and/or $\alpha-1,6$ linkages in a defined linear sequence. In addition the $\alpha$ - and $\beta$ Schardinger dextrins (cyclic, $\alpha-1,4$ linked oligosaccharides) have been included in this study. As a result of the present investigation it has been possible to compare individual members in homologous series of oligosaccharides and to examine by gel filtration chromatography isomeric, structurally related oligosaccharides composed of 2-27 glucose residues ( $\mathrm{MW}=342-4392)$. Since it has been disclosed that isomeric oligosaccharides may have different gel filtration chromatographic properties, it has also been the object of the present study to correlate the observed position of a given oligosaccharide in the elution profile with the structure of that oligosaccharide. In addition we have assumed that the position in the elution profile reflects the size of these oligosaccharides in solution and may be taken as a measure of their "hydrodynamic volume * relative to other oligosaccharides. In this respect we find that the malto-oligosaccharides offer a convenient source of reference which may facilitate comparison of results obtained in different laboratories. 


\section{ACKNOWLEDGEMENTS}

We are grateful to professor DEXTER FRENCH (Iowa State University) for helpful discussions in the early stages of this work. The digestion by isopullulanase was kindly performed by Dr. YOShIYUKI SaKano (Tokyo Noko University). Sincere thanks are due to Mrs. ANNELISE ABEL, Mrs. Nancy Gammelby and Mr. Henrik THOMSEN for valuable technical assistance. The authors also wish to thank Mr. B. AHRENSTLARSE:N, Research Manager, for excellent working conditions.

\section{REFERENCES}

1. Bathgate, G. N.: Isolation and characterisation of panose and isopanose from wort and beer. Chem. Ind. (London) 520-521 (1969)

2. BLY, D. D., K. A. Boni, M. J. R. CANTOW, J. CAZES, D. J. Harmon, J. N. Little \& E. D. WEIR: Proposed recommended practice for gel permeation chromatography terms and relationships. Polymer Letters 9: 401-411 (1971)

3. Brown, W. \& K. Chitumbo: Preparation of mannodextrins and their separation by gel chromatography. J. Chromatogr. 66: 370-374 (1972)

4. CarteR, J. H. \& E. Y. C. LeE: Adsorption chromatography of Schardinger dextrins on Sephadex G-15. Anal. Biochem. 39: 521-527 (1971)

5. DellweG, H. \& M. John: Über die Wirkungsweise stärkeabbauender Enzyme. Monatsschr. Brau. 25: 271-277 (1972)

6. Dhllweg, H., M. John \& G. Trenel: Gel permeation chromatography of maltooligosaccharides at different temperatures. J. Chromatogr. 57: 89-97 (197l).

7. DellweG, H., M. John \& G. Trenel: Chromatography of fermentable sugars and dextrins in wort and beer, using polyacrylamide gel. Proc. Am. Soc. Brew. Chem. 1970, 154-162 (1971).

8. Determann, H.: Gelchromatographie, p. 72. Springer - Verlag (Berlin) 1967.

9. Enevoldsen, B. S. \& F. SChmidt: Dextrins in brewing. Studies on the singly-branched and multiply-branched dextrins in brewing. J. Inst. Brew. 80: 520-533 (1974)

10. Enevoldsen, B. S. \& F. Schmidt: The formation of $\alpha-1,4: \alpha-1,6$-linked oligosaccharides derived from pullulan. Biochem. Soc. Trans. 3: 87-89 (1975)
11. John, M., G. Trenel \& H. Dellweg: Quantitative chromatography of homologous glucose oligomers and other saccharides using polyacrylamide gel. J. Chromatogr. 42: 476-484 (1969)

12. Laurent, T. C. \& J. Killander: A theory of gel filtration and its experimental verification. J. Chromatogr. 14: 317-330 (1964)

13. Lloyd, K. O., E. A. Kabat, E. J. Layug \& F. GrUEzo: Immunochemical studies on blood groups. XXXIV. Structures of some oligosaccharides produced by alkaline degradation of blood group $\mathrm{A}, \mathrm{B}$, and $\mathrm{H}$ substances. Biochemistry 5: 1489-150I (1966)

14. Pontis, H. G.: Separation of fructosans by gel filtration. Anal. Biochem. 23: 331-333 (1968)

15. Schmidt, F. \& B. S. Enevolosen: Gel filtration chromatography of $\alpha-1,4$ and/or $\alpha-1,6$ glucosidic linked oligosaccharides. 10th FEBS (Fed. Eur. Biochem. Soc.) Meeting, Paris, Abstract 917 (1975)

16. Trénel, G. \& C. C. EmEIS: Analyse und Charakterisierung von Glucosesirup mit Hilfe der Gelchromatographie. Staerke 22: 188-191 (1970)

17. Trenel, G., M. John \& H. Dellweg: Gel chromatographic separation of oligosaccharides at elevated temperature. FEBS (Fed. Eur. Biochem. Soc.) Letters 2: 74-76 (1968)

18. UMEkı, K. \& T. Yamamoto: Structures of branched dextrins produced by saccharifying $\alpha$ amylase of Bacillus subtilis. J. Biochem. (Tokyo) 72: 1219-1226 (1972)

19. Umeki, K. \& T. Yamamoto: Structures of multibranched dextrins produced by saccharifying aamylase from starch. J. Biochem. (Tokyo) 78 : $897-903$ (1975) 